\title{
Melting processes and mantle sources of lavas on Mercury
}

\author{
Olivier Namur ${ }^{\mathrm{a}, *}$, Max Collinet ${ }^{\mathrm{b}}$, Bernard Charlier $^{\mathrm{a}, \mathrm{c}}$, Timothy L. Grove ${ }^{\mathrm{b}}$, Francois Holtz ${ }^{\mathrm{a}}$, \\ Catherine McCammon ${ }^{\mathrm{d}}$ \\ a Institut für Mineralogie, Leibniz Universität Hannover, 30167 Hannover, Germany \\ ${ }^{\mathrm{b}}$ Massachusetts Institute of Technology, Department of Earth, Atmospheric, and Planetary Sciences, Cambridge, MA 02139, USA \\ ${ }^{\mathrm{c}}$ Department of Geology, University of Liège, 4000 Sart Tilman, Belgium \\ d Bayerisches Geoinstitut, University of Bayreuth, 95440 Bayreuth, Germany
}

\section{A R T I C L E I N F O}

\section{Article history:}

Received 10 August 2015

Received in revised form 12 November 2015 Accepted 24 January 2016

Available online $\mathrm{xxxx}$

Editor: C. Sotin

\section{Keywords:}

MESSENGER

volcanism

phase equilibria

equilibrium melting

sulfur

\begin{abstract}
A B S T R A C T
The MESSENGER spacecraft provided geochemical data for surface rocks on Mercury. In this study, we use the major element composition of these lavas to constrain melting conditions and residual mantle sources on Mercury. We combine modelling and high-temperature $\left(1320-1580^{\circ} \mathrm{C}\right)$, low- to high-pressure ( 0.1 to $3 \mathrm{GPa}$ ) experiments on average compositions for the Northern Volcanic Plains (NVP) and the high-Mg region of the Intercrater Plains and Heavily Cratered Terrains (High-Mg IcP-HCT). Near-liquidus phase relations show that the S-free NVP and High-Mg IcP-HCT compositions are multiply saturated with forsterite and enstatite at $1450^{\circ} \mathrm{C}-1.3 \mathrm{GPa}$ and $1570^{\circ} \mathrm{C}-1.7 \mathrm{GPa}$, respectively. For S-saturated melts (1.5-3 wt.\% S), the multiple saturation point (MSP) is shifted to $1380^{\circ} \mathrm{C}-0.75 \mathrm{GPa}$ for NVP and $1480^{\circ} \mathrm{C}-0.8 \mathrm{GPa}$ for High-Mg IcP-HCT. To expand our experimental results to the range of surface compositions, we used and calibrated the pMELTS thermodynamic calculator and estimated phase equilibria of $\sim 5800$ compositions from the Mercurian surface and determined the $P-T$ conditions of liquid-forsterite-enstatite MSP $\left(1300-1600^{\circ} \mathrm{C} ; 0.25-1.25 \mathrm{GPa}\right)$. Surface basalts were produced by 10 to $50 \%$ partial melting of variably enriched lherzolitic mantle sources. The relatively low pressure of the olivine-enstatite-liquid MSP seems most consistent with decompression batch melting and melts being segregated from their residues near the base of Mercury's ancient lithosphere. The average melting degree is lower for the young NVP $(0.27 \pm 0.04)$ than for the older ICP-HCT $(0.46 \pm 0.02)$, indicating that melt productivity decreased with time. The mantle potential temperature required to form Mercurian lavas and the initial depth of melting also decreased from the older High-Mg IcP-HCT terrane $\left(1650^{\circ} \mathrm{C}\right.$ and $360 \mathrm{~km}$ ) to the younger lavas covering the NVP regions $\left(1410^{\circ} \mathrm{C}\right.$ and $\left.160 \mathrm{~km}\right)$. This evolution supports strong secular cooling of Mercury's mantle between 4.2 and $3.7 \mathrm{Ga}$ and explains why very little magmatic activity occurred after $3.7 \mathrm{Ga}$.
\end{abstract}

(c) 2016 Elsevier B.V. All rights reserved.

\section{Introduction}

One of the major findings based on data from the MESSENGER spacecraft is that volcanism at the surface of Mercury was widespread (Head et al., 2011; Denevi et al., 2013; Marchi et al., 2013; Thomas et al., 2014). The MESSENGER imagery revealed that surface volcanism produced kilometer-thick deposits (Head et al., 2011; Klimczak et al., 2012; Byrne et al., 2013). Based on the density of craters across the planet, it has been estimated that the whole surface of Mercury was resurfaced by volcanic activity and that the secondary volcanic crust was formed between 4.2 and 3.7 Ga (Weider et al., 2012; Marchi et al., 2013). A large portion

\footnotetext{
* Corresponding author.

E-mail address: o.namur@mineralogie.uni-hannover.de (O. Namur).
}

of the planet $(\sim 27 \%)$ is dominated by crater-poor plains, with the largest occupying $\sim 6 \%$ of the planet surface (Northern Volcanic Plains).

The compositions of primitive melts provide the principal evidence for interpreting the conditions of magma generation for which little information currently exists. The major element composition of the lavas of Mercury can be used to decode mantle melting processes and mantle sources. These lavas may have been produced by remelting of cumulates of a solidified magma ocean (Brown and Elkins-Tanton, 2009; Charlier et al., 2013; Vander Kaaden and McCubbin, 2016) or may represent melts of an undifferentiated primordial mantle source region (Zolotov et al., 2013; Malavergne et al., 2014). The observed melts of the Mercurian mantle provide a record of the large-scale differentiation of the planet and the formation of the $\sim 35 \mathrm{~km}$ thick magmatic crust (Padovan et al., 2015). Although the bulk composition of the Mer- 
curian mantle is poorly constrained, it has been suggested that it may be similar to the silicate fraction of metal-rich chondritic material (enstatite chondrite (EH) and/or bencubbinite (CB); Taylor and Scott, 2003; Malavergne et al., 2010).

In this study, experiments and modelling are used to link the composition of the volcanic secondary crust with the mantle source materials. We used chemical information from MESSENGER (Weider et al., 2012, 2015; Peplowski et al., 2015) to calculate two average compositions representative of the High-Mg regions and the Northern Volcanic Plains. Based on high-pressure, hightemperature experiments, we discuss phase equilibria of Mercurian basalts and, in particular, we identified forsterite-enstatite-liquid multiple saturation points (MSP) that we interpret as the conditions of mantle-melt equilibration prior to eruption (Asimow and Longhi, 2004). We also discuss the role of sulfur on phase equilibria of Mercurian mantle melts. Using thermodynamic modelling with the MELTS/pMELTS algorithms, we calculated hightemperature phase equilibria of $\sim 5800$ compositions from Mercury's crust (Weider et al., 2015), corrected them empirically for the effect of sulfur, and used these data to infer the present-day mineralogy of the Mercurian mantle as well as the range of pressure and temperature conditions for melting. We also discuss the thermal evolution of the Mercurian mantle between 4.2 and $3.7 \mathrm{Ga}$ and suggest that surface lavas were produced by melting material of variably enriched lherzolitic sources.

\section{Compositional variability at the surface of Mercury}

The surface of Mercury is Mg-rich and Al-, Ca- and Fe-poor compared to terrestrial and lunar crustal material (Weider et al., 2015). It is assumed to be dominated by Mg-rich silicate minerals (forsterite, enstatite), plagioclase, sulfides [( $\mathrm{Ca}, \mathrm{Mg}, \mathrm{Fe}) \mathrm{S}]$ and possibly minor Fe-silicides (Weider et al., 2012, 2014).

Based on XRS measurements acquired during solar flares from April to December 2011, two main geochemical provinces were discriminated (Weider et al., 2012; Fig. 1): (1) the Northern Volcanic Plains (NVP) with low $\mathrm{Mg} / \mathrm{Si}$ ratios, $\mathrm{Ca} / \mathrm{Si}$ ratios and $\mathrm{S} / \mathrm{Si}$ ratios and high $\mathrm{Al} / \mathrm{Si}$ ratios; (2) the Intercrater Plains and Heavily Cratered Terrains (IcP-HCT) with, on average, higher $\mathrm{Mg} / \mathrm{Si}$ ratios, $\mathrm{Ca} / \mathrm{Si}$ ratios and $\mathrm{S} / \mathrm{Si}$ ratios and lower $\mathrm{Al} / \mathrm{Si}$ ratios. Based on analyses with better spatial resolutions (April 2011 to December 2013), the geochemical subdivision of Mercury's surface has been refined (Fig. 1). The NVP is subdivided into two regions: the low-Mg NVP at latitudes higher than $60^{\circ} \mathrm{N}$ and the high-Mg NVP $\left(\sim 30^{\circ} \mathrm{W}-100^{\circ} \mathrm{E} ; \sim 30^{\circ}-60^{\circ} \mathrm{N}\right)$. The IcP-HCT is more complicated and can broadly be subdivided into a high-Mg region, which may contain an internal high-Mg and high-Ca region and a rather heterogeneous intermediate region. $\mathrm{K}$ and $\mathrm{Na}$ are low in IcP-HCT $(K<1000 \mathrm{ppm} ; \mathrm{Na} / \mathrm{Si}: 0.10 \pm 0.01)$ and high in high-Mg NVP $(K>1200 \mathrm{ppm}$ and $\mathrm{Na} / \mathrm{Si}: 0.12 \pm 0.02)$ and even higher in lowMg NVP $(K>1500 \mathrm{ppm}$; Na/Si: $0.19 \pm 0.03$; Peplowski et al., 2012, 2014). Mercury's surface also shows several Smooth Plains (SP) including the Caloris basin, the Rachmaninoff basin, and the high-Al Smooth Plain. Sulfur is generally higher in regions with high $\mathrm{Mg} / \mathrm{Si}$ and $\mathrm{Ca} / \mathrm{Si}$ ratios (IcP-HCT) and lower in NVP (Weider et al., 2015). As shown in Fig. 1, the different geochemical terranes cannot be related to each other by a process of fractionation or accumulation of common minerals such as forsterite and enstatite, suggesting that lavas at the surface of the planet may represent primary mantle-derived melts (Fig. 1).

For this study, we recalculated surface compositions (Fig. 2 and Fig. S1) using the most recent maps produced from MESSENGER XRS data (Weider et al., 2015). We focused on the northern hemisphere for which the spatial resolution of MESSENGER measurements is the highest. We combined individual maps of $\mathrm{Mg} / \mathrm{Si}, \mathrm{Ca} / \mathrm{Si}$, $\mathrm{Al} / \mathrm{Si}$ and $\mathrm{S} / \mathrm{Si}$ and only worked on pixels for which those 4 ratios

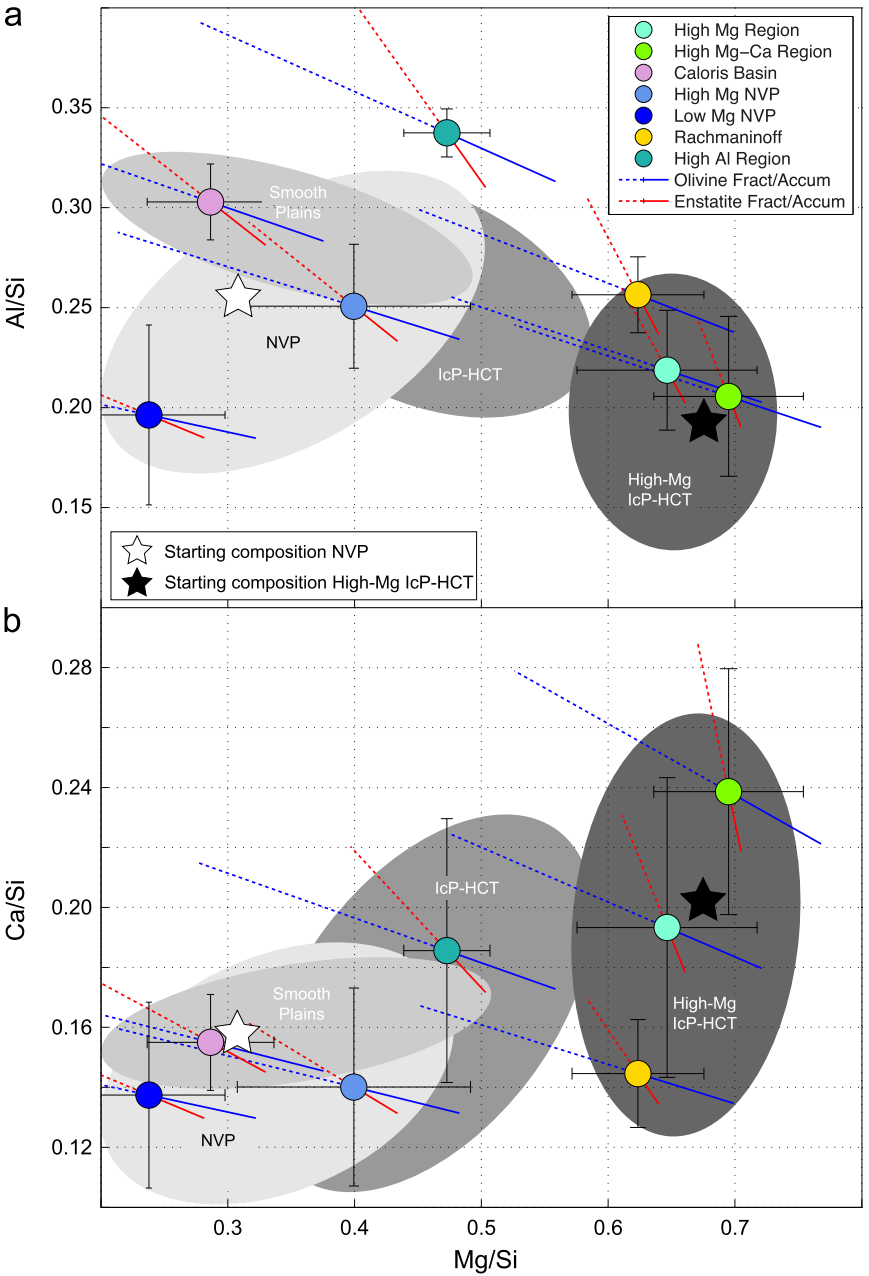

Fig. 1. Elemental weight ratios inferred from MESSENGER XRS data. (a) Al/Si versus $\mathrm{Mg} / \mathrm{Si}$. (b) $\mathrm{Ca} / \mathrm{Si}$ versus $\mathrm{Mg} / \mathrm{Si}$. Colored circles show average compositions of the geochemical terranes identified by Weider et al. (2015). The $1 \sigma$ error bars are shown for each terrane. Lines radiating from each symbol show the compositional effect of accumulating (plain line) forsterite (blue) or enstatite (red) or fractionating (dashed line) olivine or enstatite. The different geochemical provinces cannot be linked to each other by these lines, indicating that their average compositions cannot be related by any process of accumulation and/or fractional crystallization. Compositional fields in grey-scale show the range of compositions of lavas from the Northern Volcanic Plains (NVP), the Smooth Plains (SP), the Intercrater Plains and Heavily Cratered Terrains (IcP-HCT) and the High-Mg IcP-HCT region inferred from pixel analyses $\left(1.25^{\circ} \times 1.25^{\circ}\right.$ pixel groups $)$ of the elemental maps of Weider et al. (2015). Black and white stars represent the starting compositions used in experiments. (For interpretation of the references to color in this figure legend, the reader is referred to the web version of this article.)

were measured. This method allows investigating only some parts of the northern hemisphere because the $\mathrm{Ca} / \mathrm{Si}$ map is not complete. We produced $>5800$ groups of 25 pixels $\left(1.25^{\circ}\right.$ latitude $\times$ $1.25^{\circ}$ longitude) that we converted to volatile-free chemical compositions $\left(\mathrm{SiO}_{2}, \mathrm{Al}_{2} \mathrm{O}_{3}, \mathrm{MgO}\right.$ and $\mathrm{CaO}$; Fig. 2). Each pixel group was assigned to the geochemical terrane in which it is located (NVP, including the low-Mg and high-Mg NVP; IcP-HCT, excluding the high-Mg region; high-Mg region of the IcP-HCT; SP, including Caloris basin and Rachmaninoff basin) to which we attributed specific concentrations for minor elements (Nittler et al., 2011; Peplowski et al., 2015). For $\mathrm{Na}_{2} \mathrm{O}$, we considered that NVP lavas have high $\mathrm{Na}_{2} \mathrm{O}$ contents ( $\mathrm{Na} / \mathrm{Si}: 0.20 ; \sim 7$ wt.\% $\mathrm{Na}_{2} \mathrm{O}$ ), SP lavas have intermediate $\mathrm{Na}_{2} \mathrm{O}$ contents $\left(\mathrm{Na} / \mathrm{Si}: 0.14 ; \sim 5\right.$ wt.\% $\left.\mathrm{Na}_{2} \mathrm{O}\right)$ and IcP-HCT lavas have lower $\mathrm{Na}_{2} \mathrm{O}$ contents (Na/Si: 0.06; $\sim 2$ wt.\% $\mathrm{Na}_{2} \mathrm{O}$; Peplowski et al., 2014). Large chemical variability is observed in calculated compositions and the lavas from different geochemical terranes significantly overlap (Fig. 2). 

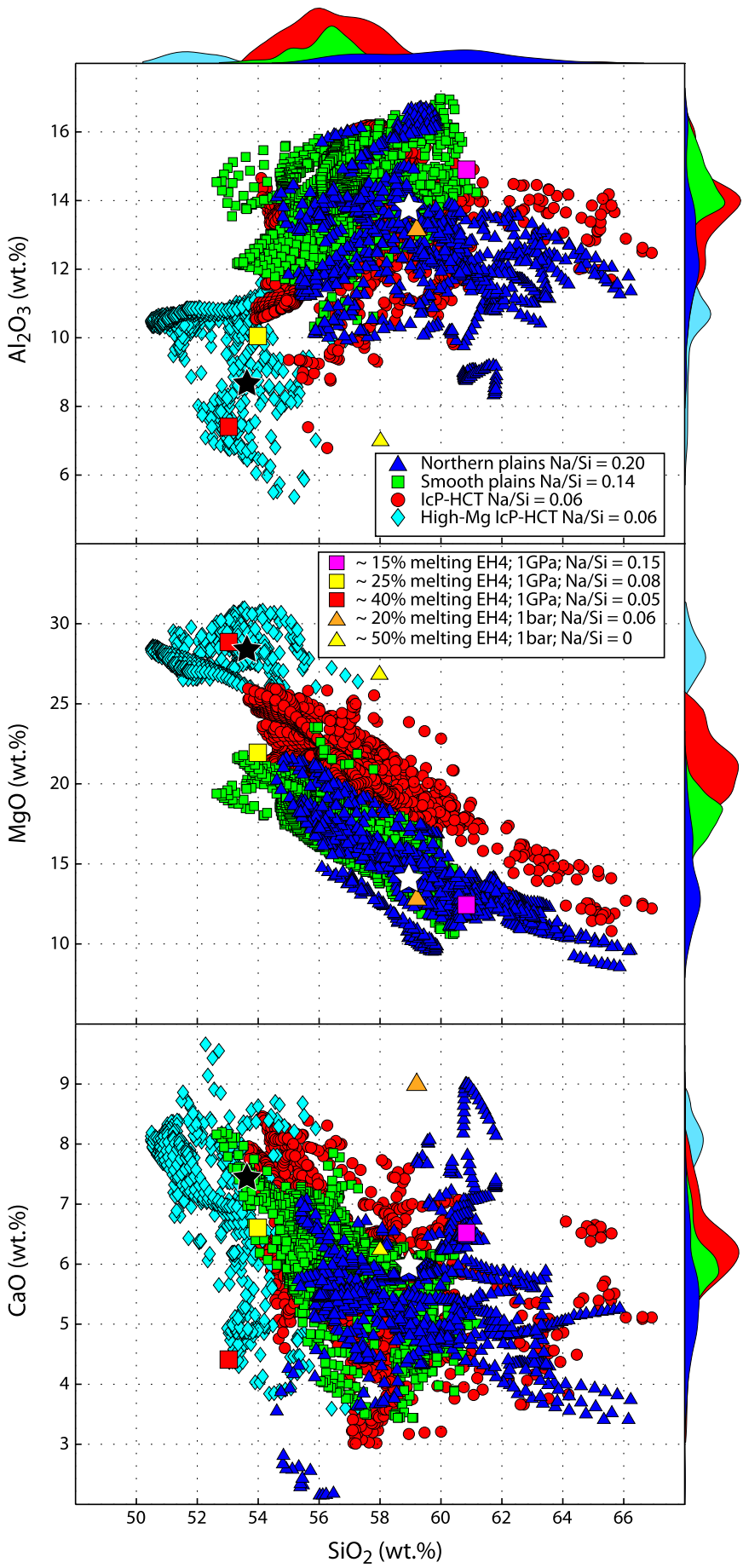

Fig. 2. Major element oxide compositions of surface lavas for $\mathrm{Al}_{2} \mathrm{O}_{3}, \mathrm{MgO}$ and $\mathrm{CaO}$ versus $\mathrm{SiO}_{2}$. Representative silicate melt compositions obtained by partial melting of an enstatite chondrite at 1 bar (McCoy et al., 1999) and 1 GPa (Boujibar et al., 2015 ) at reducing conditions ( $\sim$ IW-4; with IW being the iron-wüstite oxygen fugacity buffer) are shown for comparison. Stars represent starting compositions for experiments (see Fig. 1). Histograms of the $X$ and $Y$ axes represent the Kernel density estimation (KDE) for each population (NVP, SP, IcP-HCT, High-Mg IcP-HCT).

\section{Experimental and modelling strategy}

\subsection{Starting compositions for experiments}

Our experimental starting compositions are based on geochemical data that were available at the beginning of this project. They correspond to XRS data presented by Weider et al. (2012). For NVP, we used 34 XRS measurements and calculated median values for the $\mathrm{Mg} / \mathrm{Si}, \mathrm{Al} / \mathrm{Si}, \mathrm{Ca} / \mathrm{Si}$ ratios and re-calculated the compositions on an oxide basis (Table 1$)$. For minor elements $\left(\mathrm{TiO}_{2}, \mathrm{MnO}, \mathrm{K}_{2} \mathrm{O}\right)$ we used data from a set of XRS measurements (Nittler et al., 2011) and GRS data (Peplowski et al., 2012) as well as average compositions of terrestrial komatiites. Our estimates for $\mathrm{TiO}_{2}$ and $\mathrm{MnO}$ are very close to values more recently obtained from new XRS analyses (Weider et al., 2014). We considered an average Na/Si ratio of 0.20 , leading to $\sim 7$ wt.\% $\mathrm{Na}_{2} \mathrm{O}$ in our NVP composition (Peplowski et al., 2014). IcP-HCT lavas span a larger compositional range than NVP and may have a broadly bimodal distribution (Charlier et al., 2013; Weider et al., 2015). We prepared a starting composition corresponding to the average composition of the High-Mg group of IcP-HCT lavas. For the High-Mg IcP-HCT composition, we used 49 XRS compositions with a $\mathrm{Mg} / \mathrm{Si}$ ratio greater than 0.6 (Table 1 ). We considered a Na/Si ratio of $0.06\left(\sim 2.7\right.$ wt.\% $\left.\mathrm{Na}_{2} \mathrm{O}\right)$ and 0.1 wt.\% of $\mathrm{K}_{2} \mathrm{O}$ (Peplowski et al., 2012, 2014). During the course of this project, new XRS data were obtained from the MESSENGER spacecraft (Weider et al., 2015) and this updated database was used to calculate the compositions shown in Fig. 2. When compared with these new data (Weider et al., 2015), we observe that our experimental NVP composition is intermediate between the high-Mg NVP and low-Mg NVP, while our experimental High-Mg IcP-HCT is very similar to the High-Mg terrane (Fig. 1).

Silicate starting compositions were produced from high-purity commercially purchased powders $\left(\mathrm{SiO}_{2}, \mathrm{TiO}_{2}, \mathrm{Al}_{2} \mathrm{O}_{3}, \mathrm{MgO}, \mathrm{MnO}\right)$. For alkalis and alkaline-earth elements, we used carbonates $\left(\mathrm{CaCO}_{3}\right.$, $\mathrm{Na}_{2} \mathrm{CO}_{3}, \mathrm{~K}_{2} \mathrm{CO}_{3}$ ) that were de-carbonated at $900^{\circ} \mathrm{C}$ for $10 \mathrm{~h}$ before we mixed them with the oxides. The reagents were mixed under ethanol in an agate mortar to assure homogeneity of the starting materials. Compositions used in experiments are given in Table 1. To reduce the sample intrinsic oxygen fugacity $\left(\mathrm{fO}_{2}\right)$, we added Si metal powder to the silicate starting material. To avoid potential $\mathrm{SiO}_{2}$-enrichment of the silicate melt during experiments due to partial oxidation of $\mathrm{Si}$, we kept the $\mathrm{Si} / \mathrm{SiO}_{2}$ ratio to 0.1 in order to control $\mathrm{fO}_{2}$ without affecting elemental ratios of the starting compositions. In most experiments, we mixed the silicate material with a metallic mixture. In sulfur-free experiments, we used pure $\mathrm{Fe}^{0}$ (Metal $\mathrm{A}$ in Table 1) while in sulfur-bearing experiments we used a mixture (Metal B) of $\mathrm{Fe}^{0}(25 \%), \mathrm{FeS}(50 \%)$ and $\mathrm{S}(25 \%)$. The silicate/metal ratio was $0.9 / 0.1$ (see additional details in Table 2).

\subsection{Experimental and analytical techniques}

Low- to medium-pressure experiments (0.1-0.7 GPa) were performed in large volume internally heated pressure vessels (IHPV) at the University of Hannover (Germany). Argon was used as the pressure medium. High-pressure experiments (0.8 to $2 \mathrm{GPa}$ ) were performed at the Massachusetts Institute of Technology (MIT; USA) and at the Bayerisches Geoinstitut (BGI; Germany) in 0.5" piston cylinder apparatuses. A comprehensive description of the experimental methods and conditions with details of temperature and pressure calibration and run procedures is included in the Experimental Methods Online (Supplementary Material). Details about the calculation of oxygen fugacity conditions are also given in Supplementary Material.

Quantitative analyses were performed using a CAMECA SX100 electron probe microanalyser (EPMA) at the University of Hannover and a JEOL 8200 EPMA at MIT. Details of the analytical techniques are presented in the Analytical Methods of the Supplementary Material.

\subsection{Thermodynamic modelling with MELTS and pMELTS}

The pMELTS thermodynamic algorithm (Ghiorso et al., 2002) was used to constrain high-temperature, high-pressure phase equilibria of Mercurian surface compositions (Fig. 2). Mercury's basalts 
Table 1

Elemental ratios for the surface compositions of Mercury and starting compositions for experiments.

\begin{tabular}{|c|c|c|c|c|c|c|c|c|c|}
\hline \multicolumn{10}{|c|}{ 1. Compositions of the silicate fractions used in experiments } \\
\hline & $\mathrm{Mg} / \mathrm{Si}$ & $\mathrm{Al} / \mathrm{Si}$ & $\mathrm{Ca} / \mathrm{Si}$ & & $\mathrm{SiO}_{2}$ & $\mathrm{Al}_{2} \mathrm{O}_{3}$ & $\mathrm{MgO}$ & $\mathrm{CaO}$ & \\
\hline NVP & $0.309 \pm 0.13$ & $0.263 \pm 0.07$ & $0.156 \pm 0.04$ & & $62.41 \pm 3.75$ & $14.65 \pm 3.36$ & $14.85 \pm 5.0$ & $6.19 \pm 1.57$ & \\
\hline High-Mg IcP-HCT & $0.682 \pm 0.07$ & $0.189 \pm 0.07$ & $0.211 \pm 0.04$ & & $53.06 \pm 2.36$ & $8.85 \pm 3.11$ & $28.05 \pm 2.39$ & $7.32 \pm 1.33$ & \\
\hline \multicolumn{10}{|c|}{ Calculated oxide compositions with sodium and minor elements ${ }^{\mathrm{b}}$} \\
\hline & $\mathrm{SiO}_{2}$ & $\mathrm{TiO}_{2}$ & $\mathrm{Al}_{2} \mathrm{O}_{3}$ & $\mathrm{MnO}$ & $\mathrm{MgO}$ & $\mathrm{CaO}$ & $\mathrm{Na}_{2} \mathrm{O}$ & $\mathrm{K}_{2} \mathrm{O}$ & Total \\
\hline NVP & 58.71 & 0.40 & 13.75 & 0.20 & 13.93 & 5.81 & 7.00 & 0.20 & 100.00 \\
\hline High-Mg IcP-HCT & 52.67 & 0.40 & 8.79 & 0.20 & 27.84 & 7.27 & 2.75 & 0.08 & 100.00 \\
\hline \multicolumn{10}{|c|}{ Synthetic starting compositions ${ }^{\mathrm{C}}$} \\
\hline NVP & 58.79 & 0.30 & 13.8 & 0.17 & 13.25 & 5.97 & 7.01 & 0.17 & 99.46 \\
\hline High-Mg IcP-HCT & 53.80 & 0.36 & 8.38 & 0.21 & 26.52 & 7.43 & 2.66 & 0.09 & 99.44 \\
\hline \multicolumn{10}{|c|}{ Normative mineralogy } \\
\hline & Feldspar & Nepheline & Diopside & Hypersthene & Olivine & Ilmenite & & & \\
\hline NVP & 58.3 & 4.5 & 17.9 & 0 & 18.8 & 0.4 & & & \\
\hline High-Mg IcP-HCT & $35.3 / 25.0$ & 0 & 18.8 & 9.3 & 36.2 & 0.4 & & & \\
\hline \multicolumn{10}{|c|}{ 2. Compositions of the metallic fractions used in experiments ${ }^{\mathrm{d}}$} \\
\hline & $\mathrm{Fe}$ & $\mathrm{S}$ & & & & & & & \\
\hline Metal A & 100 & - & & & & & & & \\
\hline Metal B & 56.7 & 43.3 & & & & & & & \\
\hline
\end{tabular}

a Calculated using elemental ratios from MESSENGER presented by Weider et al. (2012).

b $\mathrm{K}_{2} \mathrm{O}$ and $\mathrm{Na}_{2} \mathrm{O}$ contents calculated from Peplowski et al. (2012, 2014); $\mathrm{TiO}_{2}$ and $\mathrm{MnO}$ contents based on Weider et al. (2014).

c Averages of glass compositions from S-free experiments that were super-liquidus (NVP: $n=4$; IcP-HCT: $n=5$ ).

d Some sulfur-free experiments were performed by mixing $90 \%$ of the silicate fraction with $10 \%$ of Metal A. S-bearing experiments were performed with $90 \%$ of the silicate fraction and $10 \%$ of Metal B. Metal B was produced by mixing Fe (25\%), FeS (50\%) and S (25\%). See additional details in Table 2.

are dominated by $\mathrm{SiO}_{2}, \mathrm{Al}_{2} \mathrm{O}_{3}, \mathrm{MgO}, \mathrm{CaO}$ and $\mathrm{Na}_{2} \mathrm{O}$, and may therefore be adequately reproduced in the simplified CMASN system. We ran several tests to estimate the accuracy of pMELTS at predicting phase equilibria in the system CMAS. We first used $\sim 60$ experiments ( 1 bar to $2 \mathrm{GPa}$ ) with forsterite $(F o)$ or enstatite (Ens) as the first liquidus phase and compared experimental phase equilibria (Andersen, 1915; Sen and Presnall, 1984; Longhi, 1987; Liu and Presnall, 1990) with those predicted by pMELTS (Fig. S2). We also used pMELTS to determine the position of the phase boundary between the liquid $($ Liq $)+$ Fo stability field and Liq + Ens stability field in the system Fo-quartz $(Q z)$-anorthite $(A n)$ (Sen and Presnall, 1984; Liu and Presnall, 1990). Our results indicate that pMELTS predicts accurately phase equilibria in the simplified CMAS system from 1 to $2 \mathrm{GPa}$. At lower pressure (1 bar), phase equilibria are better predicted with MELTS (Ghiorso and Sack, 1995) (Fig. S3).

Both MELTS and pMELTS predict liquidus temperatures with a significant error when compared to experimental data (pMELTS, Standard Error of Estimates (SEE): $\pm 35^{\circ} \mathrm{C}$; MELTS, SEE: $\pm 37^{\circ} \mathrm{C}$; Figs. S2 and S3). To minimize this error, we used experiments from this study (Table 2) together with $\sim 400$ experiments from the CMAS and CMASN (Fig. S4) and regressed an equation predicting liquidus temperature as a function of pressure and critical compositional parameters. We adopted a Gibbs phase rule inspired empirical model (Till et al., 2012). Experiments in CMAS and CMASN have 4-5 components and are usually saturated with Fo and/or Ens \pm diopside $(D i) \pm$ Feldspar (Feld) or spinel (Sp). We therefore restricted our variables to 2-4 compositional parameters in addition to pressure. After extensive search, we found that $\mathrm{SiO}_{2}$, $\mathrm{MgSi} \#$ (wt.\% $\left[\mathrm{MgO} /\left(\mathrm{MgO}+\mathrm{SiO}_{2}\right]\right), \mathrm{AlSi} \#=\left[\mathrm{wt} . \%\left[\mathrm{Al}_{2} \mathrm{O}_{3} /\left(\mathrm{Al}_{2} \mathrm{O}_{3}+\right.\right.\right.$ $\left.\mathrm{SiO}_{2}\right]$ ) and $\mathrm{NaCa}$ (wt.\% $\left[\mathrm{Na}_{2} \mathrm{O} /\left(\mathrm{Na}_{2} \mathrm{O}+\mathrm{CaO}\right]\right)$ give the best results. The model coefficients are given in Supplementary Material (Fig. S4). With these coefficients, we obtain a SEE of $\pm 16^{\circ} \mathrm{C}$ but the liquidus temperature of more than $50 \%$ of the experiments is predicted to $\pm 10^{\circ} \mathrm{C}$. Another potential issue with the use of pMELTS is the high $\mathrm{Na}_{2} \mathrm{O}$ content of Mercurian magmas. Experiments in the CMASN system (Walter and Presnall, 1994) were performed at temperatures close to the solidus (liquid fraction $(F)$ : $0-0.3$ ) and are therefore not adequate to test the reliability of pMELTS in calculating liquidus phase equilibria. We therefore compared our experimental results (NVP $\sim 7$ wt.\% $\mathrm{Na}_{2} \mathrm{O}$; High-Mg IcP-HCT $\sim 3$ wt.\% $\mathrm{Na}_{2} \mathrm{O}$ ) with those calculated by pMELTS on identical compositions. When corrected for temperature (see above), we found that pMELTS reproduces the experimentally determined Liq-Fo-Ens MSP to $\pm 0.1 \mathrm{GPa}$ and $\pm 20^{\circ} \mathrm{C}$ (Fig. S5).

In this study, we produced metastable inverse phase diagrams for each composition shown in Fig. 2 using MELTS and pMELTS, and calculated saturation curves for olivine, orthopyroxene, clinopyroxene and feldspar. Calculations were performed from 0.5 to $3 \mathrm{GPa}$ with pressure increments of 250 bars and from 1900 to $1200^{\circ} \mathrm{C}$ with temperature increments of $2^{\circ} \mathrm{C}$.

\section{Results}

\subsection{Experimental compositions and high-pressure phase relations}

All the experiments performed for this study contain silicate glass, $\pm F o$ and/or Ens \pm metallic and sulfide melts (FeSi and/or FeS). Textures of the experiments suggest that run durations (Table 2) were long enough to reach equilibrium. Enstatite and forsterite are homogeneous, form euhedral crystals with grain size ranging from 5 to $500 \mu \mathrm{m}$. They are homogeneously distributed in experimental charges obtained in the pressure range of 0.1-0.7 GPa while they are usually observed along the edges of the charge in piston cylinder experiments. Metal and sulfide melts form rounded globules (50 to $500 \mu \mathrm{m}$ ). Except in some high-pressure experiments, no quench crystals are observed in the silicate melt. In contrast, sulfide melts usually show $\mu \mathrm{m}$-scale tablet- or lamellashaped crystals typical for quench microstructures. Although these quench phases are usually too small to be analyzed by EPMA, they appear to be Fe-, Mn-, Cr-bearing monosulfide crystals. Backscattered electron images of representative experimental charges are shown in Fig. S6. Oxygen fugacity conditions during experiments are in the range of IW-4.6 to IW-6.9 (Table 2). For some experiments in which we did not add a metallic phase, oxygen fugacity conditions were estimated by comparison with those obtained in Fe-bearing experiments.

Most experiments were relatively close to the liquidus so that glass compositions are moderately affected by the crystallization of Fo and Ens. Mineral, melt, metallic alloy and sulfide melt compositions are presented in Table S1 (Supplementary Material). For NVP, glasses range in composition from 57.5 to $60.7 \mathrm{wt} . \% \mathrm{SiO}_{2}$, 
Table 2

Experimental conditions and run products.

\begin{tabular}{|c|c|c|c|c|c|c|c|c|c|c|}
\hline Run & Laboratory & Device & $\begin{array}{l}T \\
\left({ }^{\circ} \mathrm{C}\right)\end{array}$ & $\begin{array}{l}P \\
(\mathrm{GPa})\end{array}$ & $\mathrm{Si} / \mathrm{SiO}_{2}{ }^{\mathrm{a}}$ & Fe, S source ${ }^{b}$ & $\begin{array}{l}\text { Time } \\
\text { (h) }\end{array}$ & $\Delta \mathrm{IW}^{\mathrm{c}}$ & $\Delta \mathrm{IW}^{\mathrm{d}}$ & Experimental phases ${ }^{\mathrm{e}}$ \\
\hline \multicolumn{11}{|c|}{ NVP without sulfur } \\
\hline A702 & BGI & PC & 1470 & 2.00 & 0.1 & $\mathrm{Fe}(\mathrm{A})$ & 5 & -6.5 & -6.5 & Liq (78), Ens (12), FeSi (10) \\
\hline C601 & MIT & PC & 1480 & 1.70 & 0.1 & - & 5 & - & -6.5 & Liq (89), Ens (1), FeSi (10) \\
\hline C600 & MIT & PC & 1400 & 1.70 & 0.1 & - & 19 & & -6.4 & Liq (82), Ens (18) \\
\hline C580 & MIT & PC & 1450 & 1.50 & 0.1 & - & 6 & - & -6.4 & Liq (98), Ens (2) \\
\hline C581 & MIT & PC & 1440 & 1.30 & 0.1 & - & 5 & - & -6.4 & Liq (96), Fo (1), Ens (3) \\
\hline B1346 & MIT & PC & 1410 & 1.00 & 0.1 & - & 5 & - & -6.5 & Liq (97), Fo (3) \\
\hline A700 & BGI & PC & 1390 & 1.00 & 0.1 & - & 5 & -6.8 & -6.6 & Liq (96), Fo (3), Ens (1) \\
\hline BV03-1 & LUH & IHPV & 1340 & 0.70 & 0.1 & - & 4 & -7.5 & -6.6 & Liq (93), Fo (7), Si (Tr) \\
\hline BV01-1 & LUH & IHPV & 1360 & 0.70 & 0.1 & - & 6 & -7.3 & -6.7 & Liq (93), Fo (7), Si (Tr) \\
\hline Y051-1 & LUH & IHPV & 1360 & 0.50 & 0.1 & - & 3 & -7.1 & -6.9 & Liq (91), Fo (9) \\
\hline Y047-1 & LUH & IHPV & 1340 & 0.50 & 0.1 & - & 6 & -7.9 & -6.7 & Liq (92), Fo (8) \\
\hline Y028-1 & LUH & IHPV & 1330 & 0.30 & 0.1 & $\mathrm{Fe}(\mathrm{A})$ & 4 & -6.8 & -6.5 & Liq (85), Fo (5), FeSi (10) \\
\hline Y044-1 & LUH & IHPV & 1310 & 0.10 & 0.1 & $\mathrm{Fe}(\mathrm{A})$ & 5 & -6.8 & -6.9 & Liq (84), Fo (6), FeSi (10) \\
\hline Y045-1 & LUH & IHPV & 1350 & 0.10 & 0.1 & - & 5 & -6.8 & -6.9 & Liq $(100)$ \\
\hline \multicolumn{11}{|c|}{ NVP with sulfur } \\
\hline A708 & BGI & PC & 1470 & 2.50 & 0.1 & $\mathrm{FeS}+\mathrm{S}(\mathrm{B})$ & 5 & -6.7 & -5.6 & Liq (80), Ens (10), FeSi (5), FeS (5) \\
\hline A711 & BGI & PC & 1420 & 1.50 & 0.1 & $\mathrm{FeS}+\mathrm{S}(\mathrm{B})$ & 5 & -6.3 & -4.9 & Liq (83), Ens (7), FeSi (5), FeS (5) \\
\hline A704 & BGI & PC & 1400 & 1.50 & 0.1 & $\mathrm{FeS}+\mathrm{S}(\mathrm{B})$ & 5 & -6.1 & -5.8 & Liq (81), Ens (9), FeS (10) \\
\hline B1337 & MIT & PC & 1410 & 1.20 & 0.1 & $\mathrm{FeS}+\mathrm{S}(\mathrm{B})$ & 5 & -6.3 & -5.1 & Liq (85), Ens (5), FeSi (5), FeS (5) \\
\hline B1336 & MIT & PC & 1400 & 1.00 & 0.1 & $\mathrm{FeS}+\mathrm{S}(\mathrm{B})$ & 4 & -6.6 & -4.9 & Liq (88), Ens (2), FeSi (5), FeS (5) \\
\hline A713 & BGI & PC & 1360 & 1.00 & 0.1 & $\mathrm{FeS}+\mathrm{S}(\mathrm{B})$ & 4 & -6.3 & -5.2 & Liq (82), Ens (8), FeSi (4), FeS (6) \\
\hline B1357 & MIT & PV & 1330 & 1.00 & 0.1 & $\mathrm{FeS}+\mathrm{S}(\mathrm{B})$ & 1 & - & - & Liq (71), Ens (19), FeSi (4), FeS (6) \\
\hline B1338 & MIT & PC & 1390 & 0.80 & 0.1 & $\mathrm{FeS}+\mathrm{S}(\mathrm{B})$ & 5 & -6.7 & -5.6 & Liq (87), Ens (3), FeSi (4), FeS (6) \\
\hline BV03-2 & LUH & IHPV & 1340 & 0.70 & 0.1 & $\mathrm{FeS}+\mathrm{S}(\mathrm{B})$ & 4 & -5.5 & -5.2 & Liq (86), Fo (4), Ens (tr), FeSi (6), FeS (4) \\
\hline BV01-2 & LUH & IHPV & 1360 & 0.70 & 0.1 & $\mathrm{FeS}+\mathrm{S}(\mathrm{B})$ & 6 & -5.2 & -5.4 & Liq (89), Fo (1), FeSi (3), FeS (7) \\
\hline Y051-2 & LUH & IHPV & 1360 & 0.50 & 0.1 & $\mathrm{FeS}+\mathrm{S}(\mathrm{B})$ & 3 & - & -5.6 & Liq (90), FeSi (3), FeS (7) \\
\hline Y047-2 & LUH & IHPV & 1340 & 0.50 & 0.1 & $\mathrm{FeS}+\mathrm{S}(\mathrm{B})$ & 6 & -5.1 & -5.1 & Liq (88), Fo (2), FeSi (4), FeS (6) \\
\hline Y028-2 & LUH & IHPV & 1330 & 0.30 & 0.1 & $\mathrm{FeS}+\mathrm{S}(\mathrm{B})$ & 4 & -5.5 & -5.6 & Liq (87), Fo (3), FeSi (5), FeS (5) \\
\hline Y044-2 & LUH & IHPV & 1310 & 0.10 & 0.1 & $\mathrm{FeS}+\mathrm{S}(\mathrm{B})$ & 5 & - & -5.7 & Liq (88), Fo (2), FeSi (4), FeS (6) \\
\hline Y045-2 & LUH & IHPV & 1350 & 0.10 & 0.1 & $\mathrm{FeS}+\mathrm{S}(\mathrm{B})$ & 5 & - & -5.8 & Liq (90), FeSi (5), FeS (5) \\
\hline \multicolumn{11}{|c|}{ High-Mg IcP-HCT without sulfur } \\
\hline C583 & MIT & PC & 1580 & 2.00 & 0.1 & - & 5 & - & -5.7 & Liq (89), Ens (11) \\
\hline C582 & MIT & PC & 1555 & 1.70 & 0.1 & - & 6 & - & -5.8 & Liq (90), Fo (5), Ens (5) \\
\hline C577 & MIT & PC & 1510 & 1.30 & 0.1 & - & 6 & - & -6.1 & Liq (79), Fo (6), Ens (15) \\
\hline C579 & MIT & PC & 1500 & 1.50 & 0.1 & - & 5 & - & -6.1 & Liq (78), Fo (10), Ens (12) \\
\hline C599 & MIT & PC & 1540 & 1.40 & 0.1 & - & 6 & - & - & Liq (95), Fo (5) \\
\hline B1354 & MIT & PC & 1520 & 1.25 & 0.1 & - & 8 & - & -6.2 & Liq (90), Fo (10), Ens (Tr) \\
\hline B1347 & MIT & PC & 1480 & 1.20 & 0.1 & - & 5 & - & -6.2 & Liq (86), Fo (14) \\
\hline B1345 & MIT & PC & 1450 & 0.80 & 0.1 & - & 4 & - & -6.5 & Liq (76), Fo (24) \\
\hline BV02-1 & LUH & IHPV & 1470 & 0.70 & 0.1 & - & 6 & -6.8 & -6.2 & Liq (86), Fo (14), Si (Tr) \\
\hline BV04-1 & LUH & IHPV & 1450 & 0.70 & 0.1 & - & 4 & -7.9 & -6.3 & Liq (81), Fo (19), Si (Tr) \\
\hline Y099 & LUH & IHPV & 1485 & 0.50 & 0.1 & $\mathrm{Fe}(\mathrm{A})$ & 5 & -7.3 & -5.9 & Liq (90), Fo (Tr), FeSi (10) \\
\hline Y049-1 & LUH & IHPV & 1470 & 0.50 & 0.1 & - & 4 & -7.8 & -6.2 & Liq (94), Fo (6) \\
\hline Y036-1 & LUH & IHPV & 1440 & 0.50 & 0.1 & $\mathrm{Fe}(\mathrm{A})$ & 4 & -8.1 & -6.5 & Liq (73), Fo (17), Qtz (Tr), FeSi (10) \\
\hline Y098 & LUH & IHPV & 1465 & 0.30 & 0.1 & $\mathrm{Fe}(\mathrm{A})$ & 4 & -6.5 & -5.9 & Liq (90), Fo (2), FeSi (10) \\
\hline Y048-1 & LUH & IHPV & 1455 & 0.30 & 0.1 & $\mathrm{Fe}(\mathrm{A})$ & 5 & -7.2 & -5.7 & Liq (92), Fo (8), FeSi (10) \\
\hline Y097 & LUH & IHPV & 1455 & 0.10 & 0.1 & $\mathrm{Fe}(\mathrm{A})$ & 4 & - & -5.8 & Liq (85), Fo (5), FeSi (10) \\
\hline Y046-1 & LUH & IHPV & 1500 & 0.10 & 0.1 & - & 5 & - & -6.0 & Liq $(100)$ \\
\hline \multicolumn{11}{|c|}{ High-Mg IcP-HCT with sulfur } \\
\hline A699 & BGI & PC & 1650 & 3.00 & 0.1 & $\mathrm{FeS}+\mathrm{S}(\mathrm{B})$ & 5 & -6.4 & -5.9 & Liq (89), Ens (1), FeSi (7), FeS (3) \\
\hline A714 & BGI & PC & 1560 & 2.00 & 0.1 & $\mathrm{FeS}+\mathrm{S}(\mathrm{B})$ & 4 & -6.7 & -6.1 & Liq (79), Ens (11), FeSi (6), FeS (4) \\
\hline B1339 & MIT & PC & 1500 & 1.00 & 0.1 & $\mathrm{FeS}+\mathrm{S}(\mathrm{B})$ & 4 & -7.6 & -4.9 & Liq (90), FeSi (5), FeS (5) \\
\hline B1342 & MIT & PC & 1440 & 1.00 & 0.1 & $\mathrm{FeS}+\mathrm{S}(\mathrm{B})$ & 4 & -6.9 & -6.2 & Liq (69), Ens (21), FeS (10) \\
\hline B1341 & MIT & PC & 1470 & 1.00 & 0.1 & $\mathrm{FeS}+\mathrm{S}(\mathrm{B})$ & 4 & -7.1 & -6.0 & Liq (87), Ens (3), FeS (10) \\
\hline B1340 & MIT & PC & 1450 & 1.00 & 0.1 & $\mathrm{FeS}+\mathrm{S}(\mathrm{B})$ & 6 & -7.5 & -5.8 & Liq (72), Ens (18), FeSi (2), FeS (8) \\
\hline B1343 & MIT & PC & 1440 & 0.80 & 0.1 & $\mathrm{FeS}+\mathrm{S}(\mathrm{B})$ & 4 & -6.7 & -6.0 & Liq (76), Ens (14), FeSi (3), FeS (7) \\
\hline BV02-2 & LUH & IHPV & 1470 & 0.70 & 0.1 & $\mathrm{FeS}+\mathrm{S}(\mathrm{B})$ & 6 & -4.7 & -5.2 & Liq (86), Fo (4), FeSi (5), FeS (5) \\
\hline BV04-2 & LUH & IHPV & 1450 & 0.70 & 0.1 & $\mathrm{FeS}+\mathrm{S}(\mathrm{B})$ & 4 & -4.9 & -4.8 & Liq (87), Fo (3), FeSi (3), FeS (7) \\
\hline Y049-2 & LUH & IHPV & 1470 & 0.50 & 0.1 & $\mathrm{FeS}+\mathrm{S}(\mathrm{B})$ & 4 & -4.9 & -4.6 & Liq (89), Fo (1), FeSi (3), FeS (7) \\
\hline Y036-2 & LUH & IHPV & 1440 & 0.50 & 0.1 & $\mathrm{FeS}+\mathrm{S}(\mathrm{B})$ & 4 & -5.6 & -5.1 & Liq (88), Fo (2), FeSi (2), FeS (8) \\
\hline Y048-2 & LUH & IHPV & 1455 & 0.30 & 0.1 & $\mathrm{FeS}+\mathrm{S}(\mathrm{B})$ & 5 & -4.9 & -4.8 & Liq (88), Fo (2), FeSi (3), FeS (7) \\
\hline Y010-2 & LUH & IHPV & 1450 & 0.10 & 0.1 & $\mathrm{FeS}+\mathrm{S}(\mathrm{B})$ & 6 & -4.9 & -4.7 & Liq (87), Fo (3), FeSi (5), FeS (5) \\
\hline Y046-2 & LUH & IHPV & 1500 & 0.10 & 0.1 & $\mathrm{FeS}+\mathrm{S}(\mathrm{B})$ & 5 & - & -6.1 & Liq (90), FeSi (2), FeS (8) \\
\hline
\end{tabular}

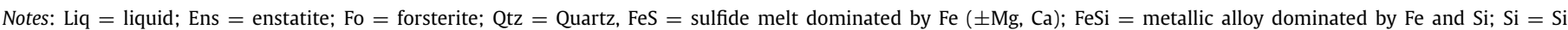
metal; IHPV = Internally heated pressure vessel; PC $=$ Piston cylinder.

a $\mathrm{Si} / \mathrm{SiO}_{2}$ ratio used to reduce the oxygen fugacity conditions.

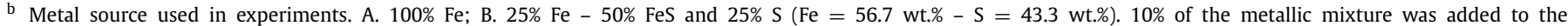
experiments.

c Oxygen fugacity relative to the iron-wüstite calculated from Fe-FeO equilibrium assuming $\gamma \mathrm{FeO}=1.5$ and $\gamma$ Fe calculated following Corgne et al. (2008).

d Oxygen fugacity relative to the iron-wüstite calculated from $\mathrm{Si}-\mathrm{SiO}_{2}$ equilibrium following Cartier et al. (2014).

e Phase proportions in percent obtained from mass balance calculations:

In runs for which no metal alloy was observed, fO ${ }_{2}$ was calculated using the average composition of metal alloys from runs A702, Y028-1, Y044-1, Y036-1 and Y048-1. Runs without calculated $\Delta \mathrm{IW}$ from Fe-FeO equilibrium have a silicate melt with FeO content below the detection limit. 


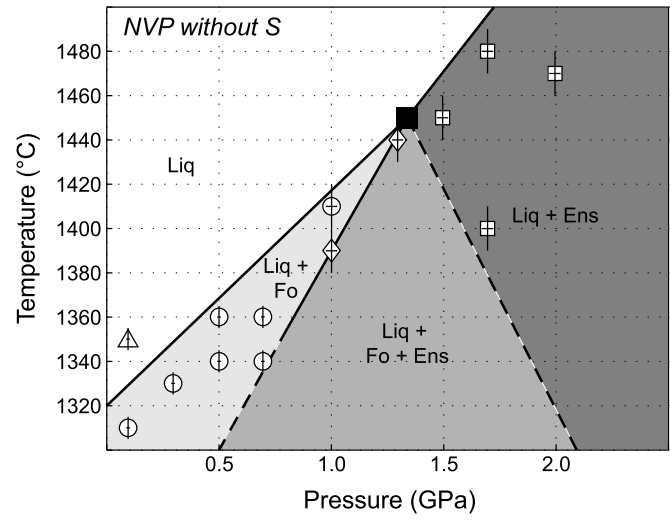

a

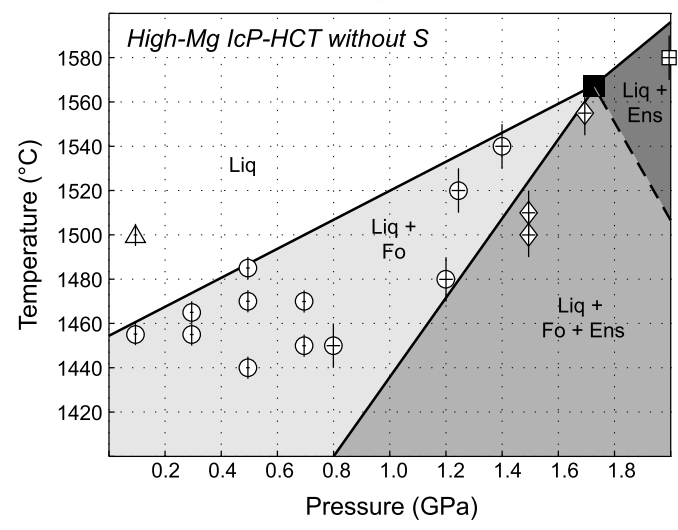

C

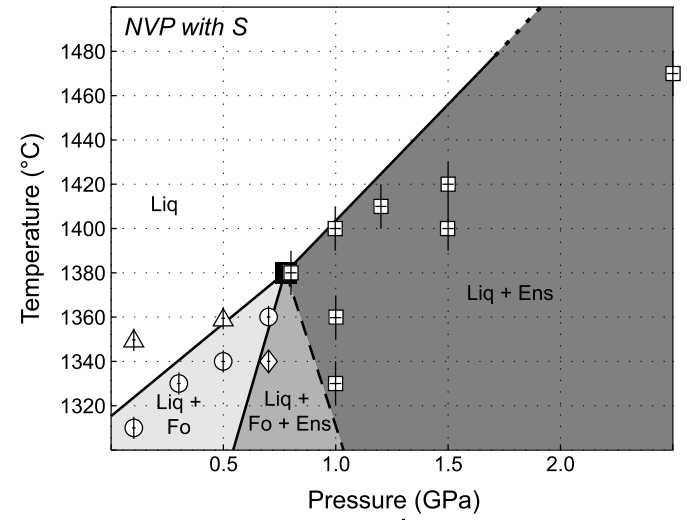

b

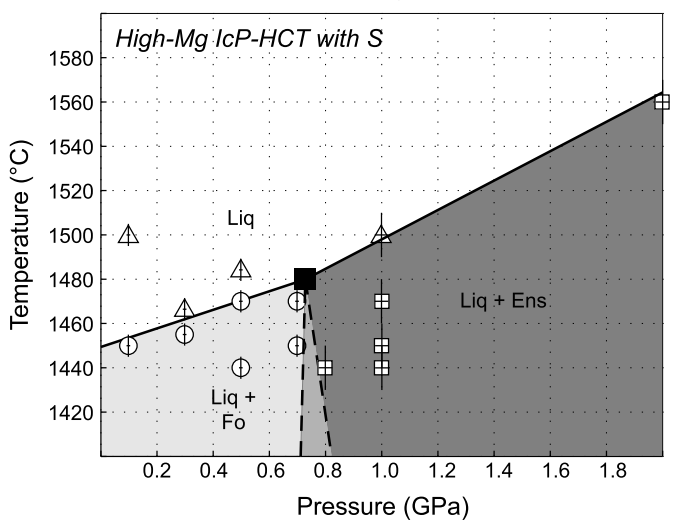

d

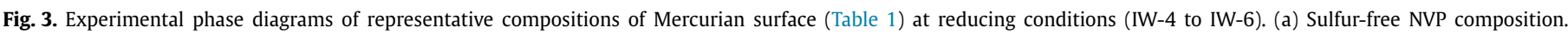

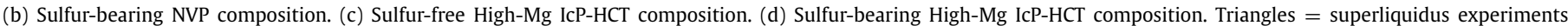

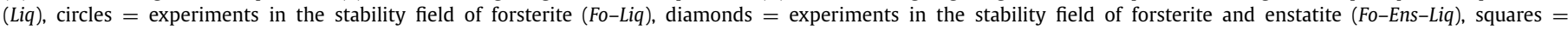
experiments in the stability field of enstatite (Ens-Liq). Vertical and horizontal black lines show experimental uncertainty for temperature and pressure.

13.5 to 17.1 wt.\% $\mathrm{Al}_{2} \mathrm{O}_{3}, 8.6$ to 14.0 wt.\% $\mathrm{MgO}$ and 5.9 to 6.7 wt.\% CaO. $\mathrm{Na}_{2} \mathrm{O}$ is high (6.9-8.4 wt.\%) and minor element concentrations $\left(\mathrm{TiO}_{2}, \mathrm{MnO}\right.$ and $\left.\mathrm{K}_{2} \mathrm{O}\right)$ are almost identical to those of the starting compositions. In the sulfur-bearing system, silicate melts contain 1.9-2.9 wt.\% S and are generally enriched in $\mathrm{MgO}$ and depleted in $\mathrm{CaO}$ compared to S-free melts. For High-Mg IcP-HCT, glasses range in composition from 53.7 to 57.5 wt.\% $\mathrm{SiO}_{2}, 7.7$ to 10.0 wt.\% $\mathrm{Al}_{2} \mathrm{O}_{3}, 19.1$ to 27.0 wt.\% $\mathrm{MgO}, 7.0$ to 10.1 wt.\% $\mathrm{CaO}$ and 2.5-3.9 wt.\% $\mathrm{Na}_{2} \mathrm{O}$. In the sulfur-bearing system, glasses contain 1.2-3.7 wt.\% S. Two experiments have less than 2 wt.\% S and we suspect that $\mathrm{S}$ may have been lost to the Pt jacket after silicate-metal equilibration. The $S$ contents in silicate melts are similar to those observed in previous studies at similar oxygen fugacity conditions (McCoy et al., 1999; Berthet et al., 2009) and support the high sulfur solubility observed at reducing conditions and high temperature (Malavergne et al., 2014). Mineral compositions match Fo and Ens end-members. There is a slight increase of the $\mathrm{Al}_{2} \mathrm{O}_{3}$ content of Ens (1-3 wt.\%) with increasing pressure. Metal alloys are dominated by Fe and Si with minor Mn, $\mathrm{Cr}$ and $\mathrm{Ni}$. In experiments with $\mathrm{Fe}$ as the metallic source (Table 2), FeSi alloys have a composition of $\sim \mathrm{Fe}_{92} \mathrm{Si}_{8}$ while in experiments with $\mathrm{Fe}+\mathrm{FeS}$, FeSi alloys are closer to $\mathrm{Fe}_{95} \mathrm{Si}_{5}$, indicating slightly more oxidizing conditions in experiments with FeS (Chabot et al., 2014). Sulfide melts are close to the FeS end-member ( 65 wt.\% $\mathrm{Fe}$ - 35 wt.\% S; average $\left.\mathrm{Fe}_{1.01} \mathrm{~S}_{0.99}\right)$ with minor amounts of $\mathrm{Ti}$ (0-3 wt.\%), Mg (0-1 wt.\%), Ca (0-2 wt.\%), Ni (0-1 wt.\%) and $\mathrm{Cr}$ (0-2 wt.\%; Supplementary Material). These compositions are similar to those produced in previous studies (Berthet et al., 2009; Chabot et al., 2014) but sulfide melts significantly richer in $\mathrm{Mg}$ and Ca were also described (McCoy et al., 1999; Malavergne et al., 2014).
Inferred phase diagrams for the compositions representative of NVP and High-Mg IcP-HCT (Tables 1 and 2) are shown in Fig. 3. In all cases, $F o$ is the first phase to crystallize at low-pressure while Ens is the first phase to crystallize at high-pressure. For the S-free NVP composition, we infer that the liquid is multiply-saturated with Fo, Ens and Liq at $\sim 1.3 \mathrm{GPa}$ and $1450^{\circ} \mathrm{C}$. For the S-bearing NVP composition, the phase boundary for Ens is lowered by $\sim 20^{\circ} \mathrm{C}$ at $1.3 \mathrm{GPa}$, while the Fo phase boundary is lowered by at least $150^{\circ} \mathrm{C}$. The Fo-Ens-Liq MSP therefore moves to lower pressure and lower temperature $\left(\sim 0.75 \mathrm{GPa}\right.$ and $\left.1385^{\circ} \mathrm{C}\right)$, relative to the S-free NVP composition. The S-free High-Mg IcP-HCT composition is multiply saturated with Fo and Ens at $\sim 1.7 \mathrm{GPa}$ and $1560^{\circ} \mathrm{C}$. For the sulfur-bearing High-Mg IcP-HCT composition, the Fo-Ens-Liq MSP moves to lower pressure and lower temperature $(\sim 0.8 \mathrm{GPa}$ and $1480^{\circ} \mathrm{C}$ ), relative to the S-free High-Mg IcP-HCT composition.

\subsection{Thermodynamic modelling of high-pressure phase equilibria}

Modelling of high-temperature, high-pressure phase equilibria with MELTS/pMELTS was performed for all the compositions shown in Fig. 2. Except for $\sim 100$ compositions from IcP-HCT with $>60$ wt.\% $\mathrm{SiO}_{2}$, MELTS and pMELTS predict Fo as the first phase to crystallize at low pressure $(0.5 \mathrm{GPa})$. In all calculations, Fo is the first liquidus phase over a significant pressure range and is then replaced by Ens at higher pressure. In Fig. 4 (and Fig. S7), we report histograms showing the distribution of Fo-Ens-Liq MSP for individual pixel groups of sulfur-free Mercury's surface. For some terranes, the distribution is pluri-modal but the median values are $\sim 1.2 \mathrm{GPa}$ and $1450^{\circ} \mathrm{C}$ for NVP lavas, $\sim 1.3 \mathrm{GPa}$ and $1460^{\circ} \mathrm{C}$ for SP lavas, $\sim 1.2 \mathrm{GPa}$ and $1460^{\circ} \mathrm{C}$ for IcP-HCT lavas and $\sim 1.75 \mathrm{GPa}$ and $1565^{\circ} \mathrm{C}$ for High-Mg IcP-HCT lavas. Median values of MSP for NVP 

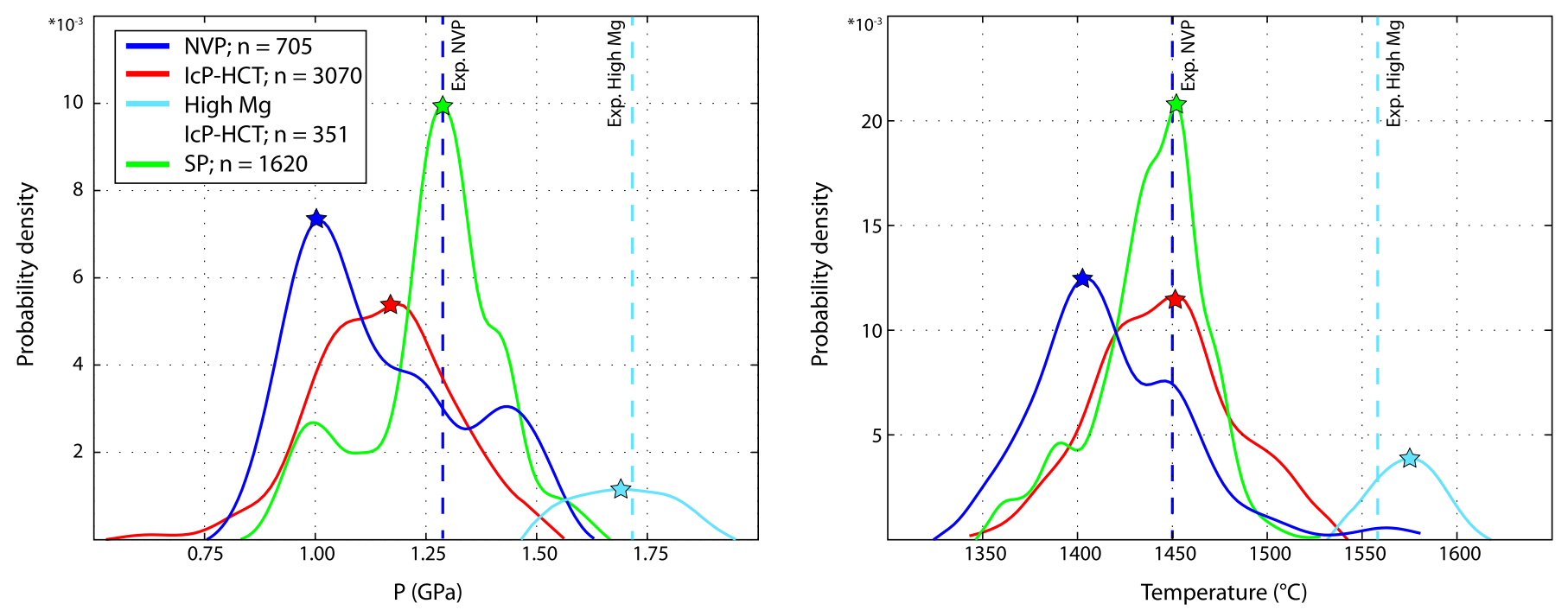

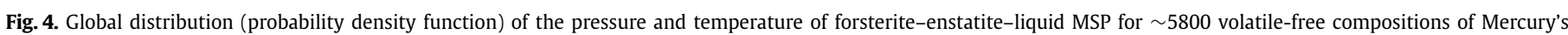

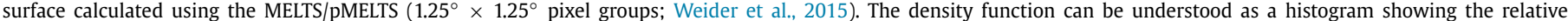

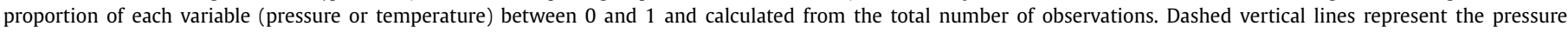

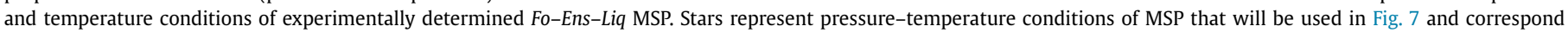
to the modes (highest probability) of the MSP distributions for each province on Mercury.

and High-Mg IcP-HCT are almost identical to the MSP observed in our experiments. However, for NVP the mode of MSP is slightly lower in pressure $(\sim 1 \mathrm{GPa})$ and temperature $\left(\sim 1410^{\circ} \mathrm{C}\right)$ than that observed in our experiments. This is due to the large chemical variability of the NVP province (Fig. 2). The effect of chemical variability is also shown in recent experiments from Vander Kaaden and McCubbin (2016) performed on a NVP composition with higher MgO content (16.5 wt.\%) than our NVP starting composition. These experiments show a Fo-Ens-Liq MSP at 1.4 GPa and $1460^{\circ} \mathrm{C}$.

\section{Discussion}

\subsection{The role of sulfur on high-pressure phase equilibria}

Phase relations of Mercurian basalts are highly sensitive to the presence of sulfur (Fig. 3). We observe that the Fo stability field contracts in presence of sulfur while the Ens stability field expands. Overall, the presence of sulfur has the effect of reducing both the pressure and temperature of the Fo-Ens-Liq MSP (NVP: $\Delta P=0.55 \mathrm{GPa} ; \Delta T=65^{\circ} \mathrm{C}$; High-Mg IcP-HCT: $\Delta P=0.95 \mathrm{GPa}$; $\Delta T=85^{\circ} \mathrm{C}$ ). The role of sulfur on phase equilibria may be understood in terms of complexing between sulfur and other elements in the silicate melt. At reducing conditions, where no Fe is present in the silicate melt, $\mathrm{S}^{2-}$ complexes with network-modifying cations $\left(\mathrm{Mg}^{2+}, \mathrm{Ca}^{2+}\right.$; Fogel, 2005; Métrich et al., 2009; Zolotov et al., 2013) and with charge-balancing cations ( $\mathrm{Na}^{+}$; Métrich et al., 2009), forming ion clusters that are distinct from the silicate network. The formation of these sulfide complexes has the effect of increasing the activity of $\mathrm{SiO}_{2}$ of the silicate melt, reducing the activity of the cations included in the complexes (e.g. $\mathrm{Ca}, \mathrm{Mg}, \mathrm{Na}$ ), and increasing the degree of melt polymerization (Fogel, 2005; Métrich et al., 2009). All these effects stabilize pyroxene with respect to olivine.

The pressure and temperature depression of the Fo-Ens-Liq MSP is stronger for the High-Mg IcP-HCT composition $(\triangle P$ : $0.95 \mathrm{GPa} ; \Delta T: 85^{\circ} \mathrm{C}$ ) than for the NVP composition ( $\Delta P: 0.55 \mathrm{GPa}$; $\Delta T: 65^{\circ} \mathrm{C}$ ). This indicates that the effect of $\mathrm{S}$ on the pressuretemperature position of the MSP is not a simple function of the melt sulfur content but also depends on the S-free bulk composition of the melt. We suggest that the larger decrease in the pressure of the MSP for the High-Mg IcP-HCT composition than for the NVP composition is related to the contrasted anorthite and nepheline components of these two compositions. As observed in simplified systems (CMAS, CMASN, Ne-Fo-Qtz; Gupta et al., 1987; Sen and Presnall, 1984; Liu and Presnall, 1990; Walter and Presnall, 1994), increasing the anorthite and nepheline components has a strong influence on the relative position of forsterite and enstatite phase boundaries and therefore on the pressure shift of the Fo-Ens-Liq MSP due to the formation of CaS, MgS and $\mathrm{Na}_{2} \mathrm{~S}$ complexes (Fig. S8).

\subsection{Mantle melting conditions}

Lava compositions from the Mercurian surface were projected in the Ca-Tschermak (CaTs)-forsterite-quartz pseudo-ternary (Fig. 5). The increase in CaTs component reflects the increase in $\mathrm{Na}_{2} \mathrm{O}$ content of the lava. The three separate groupings occur because we assigned a fixed value $\mathrm{Na} / \mathrm{Si}$ ratio to each one. This results in $\sim 2.7$ wt.\% $\mathrm{Na}_{2} \mathrm{O}$ for IcP-HCT lavas, $\sim 5$ wt.\% $\mathrm{Na}_{2} \mathrm{O}$ for SP lavas and $\sim 7$ wt.\% $\mathrm{Na}_{2} \mathrm{O}$ for NVP lavas. The compositional trends within each group do not follow olivine subtraction lines which we interpret as a further indication that magmas have not experienced significant low pressure fractional crystallization and potentially represent primary mantle-derived melts. Most compositions fall within the low pressure (1 bar) Fo stability field (determined using experimental data from CMAS) or within the extension of the Fo stability field towards the CaTs component (Fig. 5). Mercurian lavas also display trends that are oblique to the Ens-Fo boundaries indicating that they do not simply represent partial melts produced isobarically along a Fo + Ens + Liq cotectic.

\subsubsection{Degrees of partial melting}

The conditions of mantle melting can be constrained from the position of the Fo-Ens-Liq MSP and an estimate of melt productivity in the mantle source. We considered that the Mercurian mantle is dominantly lherzolitc (Malavergne et al., 2010) and calculated melt isopleths between the solidus and liquidus surfaces of the silicate fraction of an EH chondrite (Katz et al., 2003; Shorttle et al., 2014). We used the MELTS/pMELTS algorithms to calculate the pressure-temperature path of the liquidus surface and we considered that the solidus of the Mercurian mantle can 


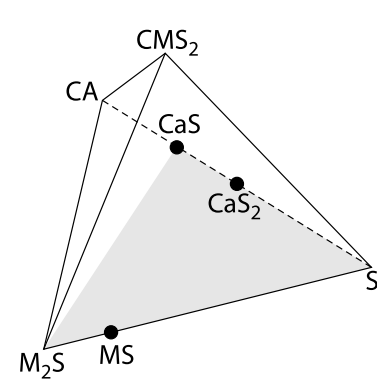

chermak
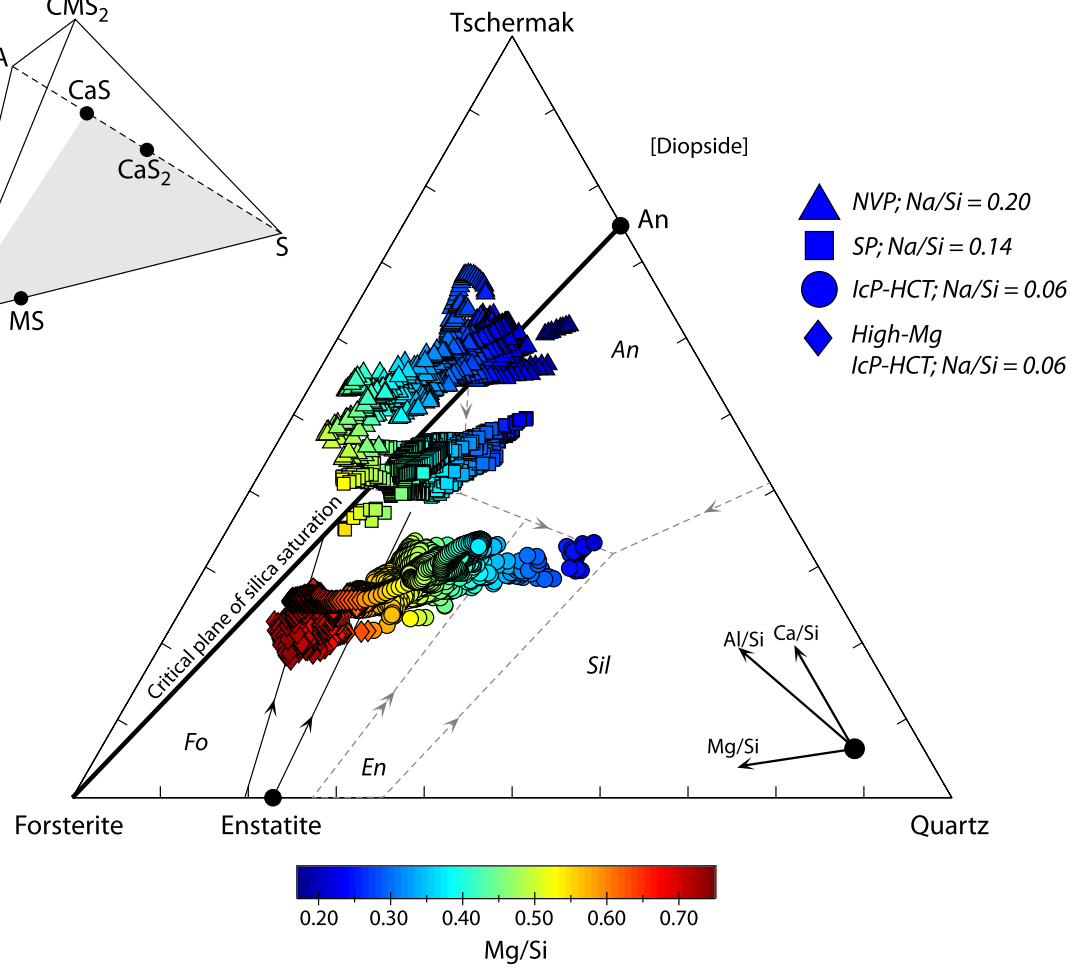

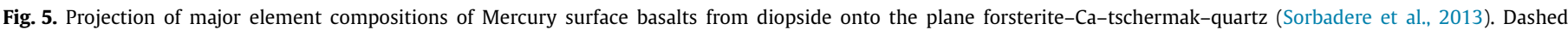

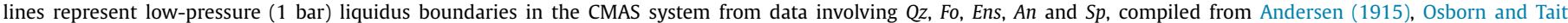

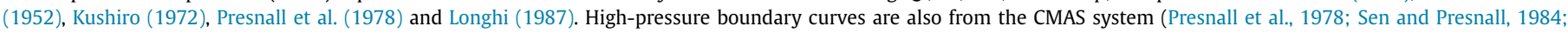
Liu and Presnall, 1990).

be closely approximated by the solidus of the CMASN system. We selected this system because it reflects the absence of iron and the high $\mathrm{Na}_{2} \mathrm{O}$ content of the Mercurian mantle (Zolotov et al., 2013; Peplowski et al., 2015). We note that the solidus of the CMASN system at $1 \mathrm{GPa}$ is similar to that experimentally determined for a bulk composition of $\mathrm{EH}$ chondrite (Berthet et al., 2009) and is thus potentially close to the solidus of the Mercurian mantle. We then used the $P-T$ conditions of the Liq-Fo-Ens MSP calculated for surface basalts to estimate the mantle melting conditions at which these magmas were produced (Fig. 6). In S-free-conditions, lavas can be produced in the mantle between 0.5 and $2.0 \mathrm{GPa}$ at temperatures between 1350 and $1600^{\circ} \mathrm{C}$ (Fig. 6a). Most lavas from NVP, SP and IcP-HCT can be explained by isobaric melting with melt fractions ranging from 0.2 to 0.4 , in agreement with the absence of clinopyroxene as a residual phase in their source regions (Hirschmann et al., 1999). The High-Mg IcP-HCT lavas would require higher melt fractions (0.4-0.5) and melting at relatively high temperature $\left(1540-1600^{\circ} \mathrm{C}\right)$.

A more realistic estimate of melting conditions includes $\mathrm{S}$ in the lava compositions (Chabot et al., 2014; Malavergne et al., 2014) and takes into account the role of $S$ on pressure and temperature conditions of the MSP. The effect of sulfur on our inferred solidus and liquidus surfaces is unknown but we assume it will be limited because $S$ in the mantle will be present as sulfide minerals with low melting temperature (Gaetani and Grove, 1999) which will form a sulfide-rich, silicate poor first melt. Further heating would then produce a S-rich silicate melt (Chabot et al., 2014; Malavergne et al., 2014). We used our sulfur-bearing experiments to adjust the pressure and temperature conditions of MSP calculated with pMELTS for S-free starting compositions. We assumed that the dominant effect of $S$ on the MSP position is from the formation of $\mathrm{CaS}$ and $\mathrm{MgS}$ complexes in the silicate melt (Fogel, 2005). We developed a simple linear relationship be- tween the $\mathrm{CaO}$ and $\mathrm{MgO}$ contents of the S-free bulk compositions and the pressure and temperature change of the MSP when $\mathrm{S}$ is present. We also considered that the sulfur at the Mercurian surface was transported as dissolved $S^{2-}$ in the silicate melt, which is likely given the high sulfur solubility in silicate melt at reducing conditions (Berthet et al., 2009; Chabot et al., 2014; Malavergne et al., 2014). When corrected for the effect of CaS and MgS complexing, MSP of Mercury's lavas range from 0.25 to $1.2 \mathrm{GPa}$ and from 1300 to $1580^{\circ} \mathrm{C}$, with most basalts produced at $\sim 0.75 \mathrm{GPa}\left(\sim 60 \mathrm{~km}\right.$ in depth) and $\sim 1400^{\circ} \mathrm{C}$. Melt fractions are relatively similar to those calculated for $\mathrm{S}$-free compositions and range from 0.1 to 0.5 , with the highest melting fractions $(>0.45)$ observed for lavas of High-Mg IcP-HCT (Fig. 6b). The formation of High-Mg IcP-HCT lavas still requires very high temperatures $\left(1450-1580^{\circ} \mathrm{C}\right)$. We note that melt compositions produced by 20 and 50\% melting of an EH chondrite meteorite (McCoy et al., 1999; Berthet et al., 2009; Boujibar et al., 2015) fall within the compositional groups of low-Mg and high-Mg Mercurian basalts (Fig. 2), supporting our estimates of melting fractions.

\subsubsection{Mantle melting processes}

The results presented in Fig. 6b imply relatively shallow melting conditions $(<1.5 \mathrm{GPa})$. The most likely process that would produce widespread, long duration volcanism on Mercury is adiabatic decompression melting that accompanies mantle convection. Melting by adiabatic decompression occurs when hotter, deeper mantle ascends from depth along an adiabat and crosses the mantle solidus (Hess, 1992). The adiabatic gradient ( $\sim 10 \mathrm{~K} / \mathrm{GPa})$ of an ascending parcel of lherzolite is much lower than the slope of the mantle solidus $(\sim 100 \mathrm{~K} / \mathrm{GPa})$, explaining why the adiabat crosses the solidus at depth (Fig. 7). Melting is driven by the thermal energy released by cooling the mantle from the temperature that would be achieved if the mantle rose along the adiabat without melting to the solidus temperature (mantle potential temperature $\left(T_{\mathrm{p}}\right)$; 


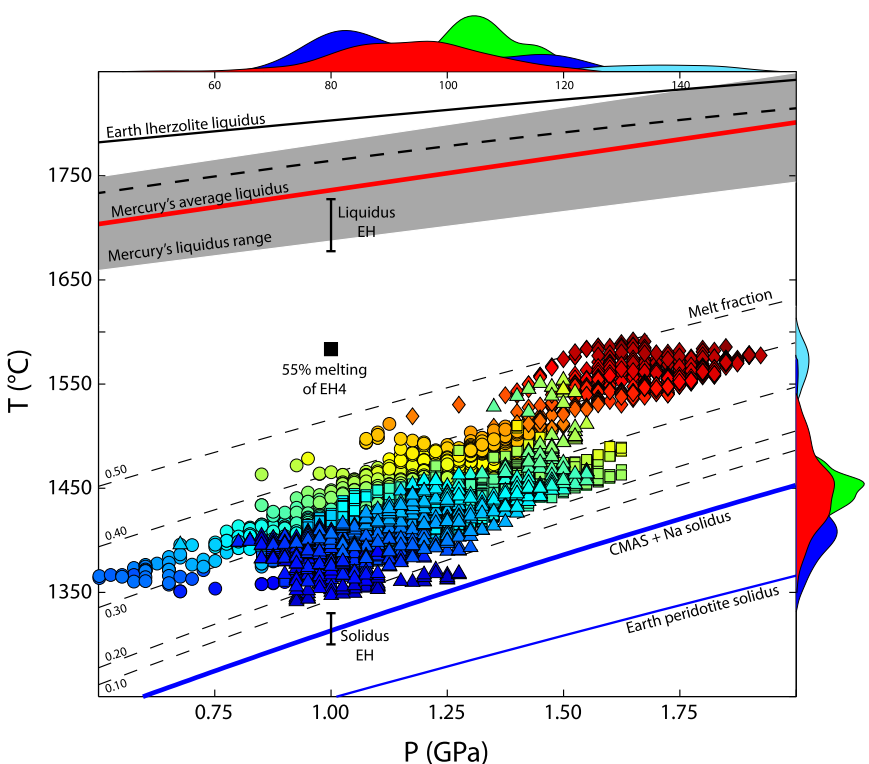

a

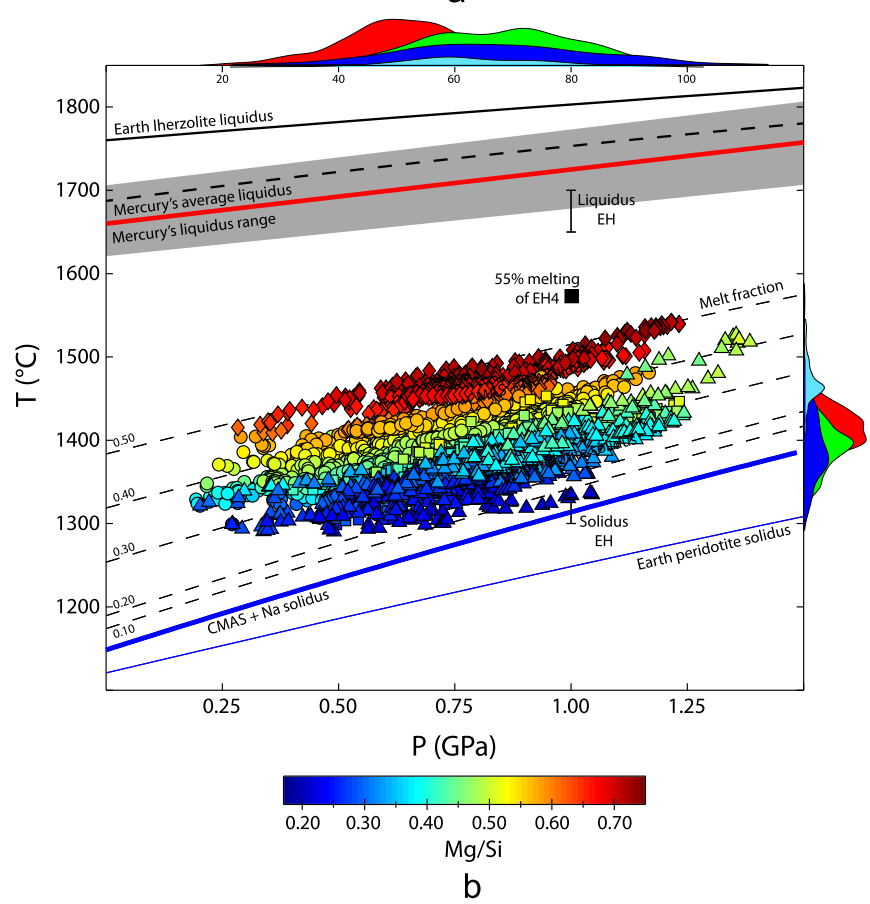

Fig. 6. Temperature $\left({ }^{\circ} \mathrm{C}\right)$ versus pressure (GPa) diagrams showing the position of the liquid-forsterite-enstatite multiple saturation points (MSP) of Mercurian lavas as calculated with the pMELTS algorithm (Ghiorso et al., 2002). (a) Calculations performed on S-free compositions. Triangles = lavas from NVP, squares = lavas from SP, circles = lavas from IcP-HCT, diamonds = lavas from HMg. (b) Corrected MSP taking into account the effect of $S$ on phase equilibria (see text for details). Dashed black lines represent melt fraction isopleths calculated after Katz et al. (2003) and Shorttle et al. (2014). We broke the melting interval between a clinopyroxene present melting interval and a clinopyroxene free interval and assumed an initial clinopyroxene mass fraction of 0.15 . We considered the solidus surface of a lherzolite in the CMAS system (Presnall et al., 1979) that we corrected for the $\mathrm{Na}_{2} \mathrm{O}$ content $(\sim 1.5$ wt.\%) of an EH chondrite (Walter and Presnall, 1994; Kiefer et al., 2015). The solidus was calculated using the following equation: $T_{\mathrm{s}}\left({ }^{\circ} \mathrm{C}\right)=1148+177 \times P(\mathrm{GPa})-12.2 \times P^{2}$. We considered the liquidus surface of an EH chondrite calculated with pMELTS. Solidus and liquidus curves for terrestrial peridotites and lherzolites are shown for comparison (Herzberg, 1983; Hirschmann, 2000; Katz et al., 2003). Vertical black lines represent liquidus and solidus temperatures of an enstatite chondrite (EH4) at $1 \mathrm{GPa}$ and reducing conditions (Berthet et al., 2009). Black symbol represents the pressure-temperature conditions at which 55\% melt is produced from EH4 (Boujibar et al., 2015). Numbers on the upper $x$-axis represent depth in km assuming that the Mercury's mantle is $400 \mathrm{~km}$ thick (Smith et al., 2012) and has an average density of $3350 \mathrm{~kg} / \mathrm{m}^{3}$ (Padovan et al., 2015). Histograms of the $X$ and $Y$ axes are as in Fig. 2.

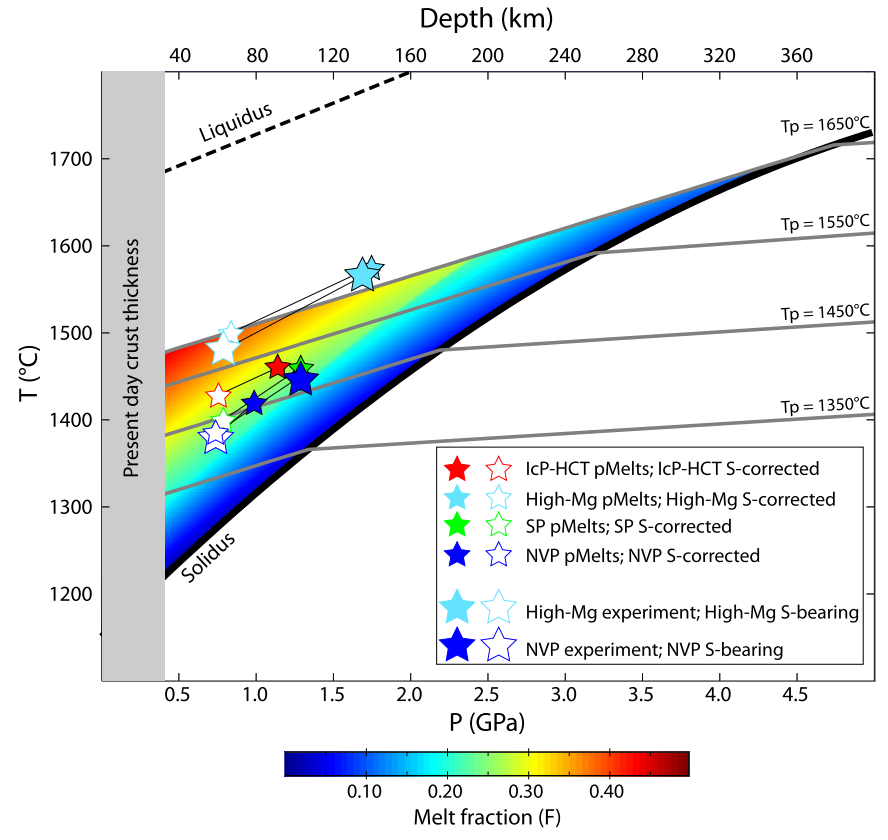

Fig. 7. Pressure-temperature diagram showing the framework of decompression melting and position of experimental liquid-forsterite-enstatite multiple saturation points (MSP) and median values of MSP calculated with pMELTS for NVP, SP and IcP-HCT (low-Mg and high-Mg) (see stars in Fig. 4). Solidus and liquidus curves are as in Fig. 6. Adiabatic paths for mantle potential temperatures $\left(T_{\mathrm{p}}\right)$ from 1350 to $1650^{\circ} \mathrm{C}$ were calculated following Shorttle et al. (2014). Melt fractions are calculated assuming adiabatic decompression of a lherzolitic mantle. The grey vertical box represents the average present day crustal thickness of Mercury (Padovan et al., 2015).

McKenzie and Bickle, 1988). The amount of melting is controlled by important thermodynamic properties of the mantle material, such as the heat capacity $\left(C_{\mathrm{p}}\right)$ and the entropy of fusion, and temperature difference between solidus and the adiabat at the depth where the melt is segregated from its source region $(\Delta T)$. We considered identical solidus and liquidus surfaces than those shown in Fig. 6 and thermodynamic properties of a lherzolite (Shorttle et al., 2014) and calculated that every 1 GPa of adiabatic decompression produces $\sim 10 \%$ of melt (Fig. 7 ). Fig. 7 shows the temperaturepressure conditions of melting from the compositionally distinct regions on Mercury. For High-Mg IcP-HCT lavas, melting begins at the greatest depths $(\sim 360 \mathrm{~km} ; 4.5 \mathrm{GPa})$ and highest temperatures $\left(\sim 1720^{\circ} \mathrm{C}, T_{\mathrm{p}}=1650^{\circ} \mathrm{C}\right)$ near the core-mantle boundary, estimated at $400 \mathrm{~km}$ (Smith et al., 2012). For IcP-HCT compositions, melting started at a depth of $\sim 200 \mathrm{~km}(\sim 2.5 \mathrm{GPa})$ at a temperature of $1550^{\circ} \mathrm{C}\left(T_{\mathrm{p}}=1510^{\circ} \mathrm{C}\right)$. For NVP and SP lavas, melting began at shallower depths $(\sim 160 \mathrm{~km} ; 2 \mathrm{GPa})$ and lower temperature $\left(1435^{\circ} \mathrm{C}, \mathrm{T}_{\mathrm{p}}=1410^{\circ} \mathrm{C}\right)$.

On Earth adiabatic decompression melting mostly occurs at mid-ocean ridges and is near-fractional. During this process, fractional melting increments are produced over a range of pressure and the melts are segregated from their residues as they are produced (Ahern and Turcotte, 1979; Klein and Langmuir, 1987). In near fractional adiabatic decompression melting, the MSP records the average pressure-temperature conditions of melting along the entire melting column. On Mercury, such a process should lead to MSP at $\sim 1$ GPa for NVP and SP, 1.25 GPa for IcP-HCT and $\sim 2.25 \mathrm{GPa}$ for the High-Mg IcP-HCT. These values are much higher than the MSP that we observed experimentally for the NVP and High-Mg IcP-HCT compositions ( $\sim 0.75 \mathrm{GPa})$. We therefore conclude that near-fractional polybaric melting was not a dominant process in the formation of Mercurian surface lavas. Another process by which adiabatic decompression may produce abundant melting is through decompression batch melting (Bowen, 1928). 


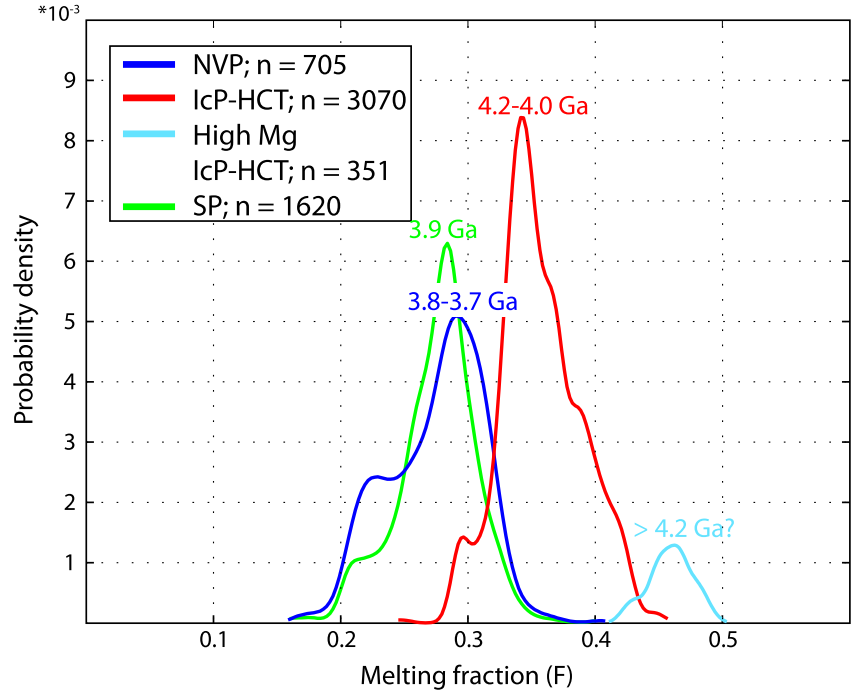

a

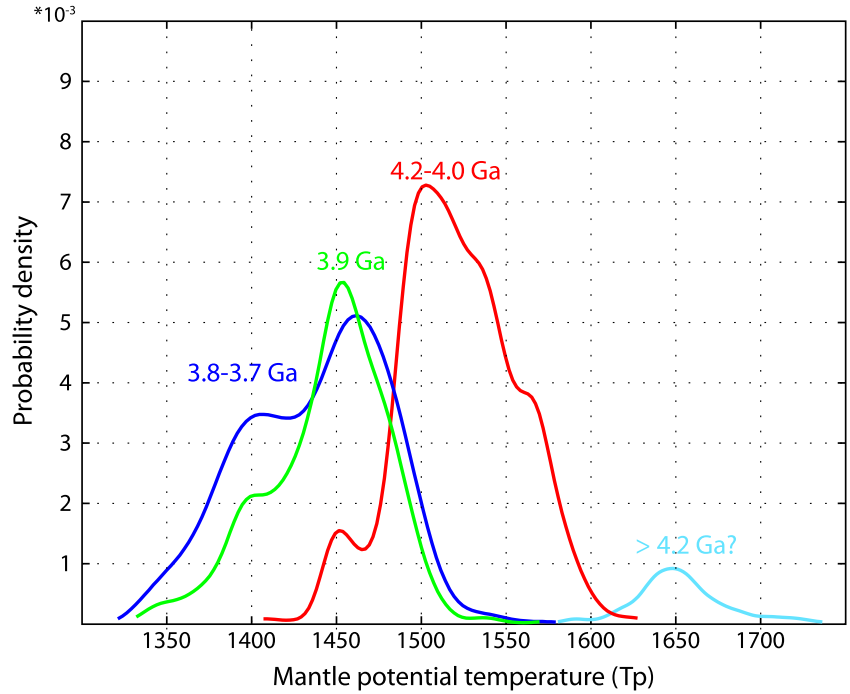

b

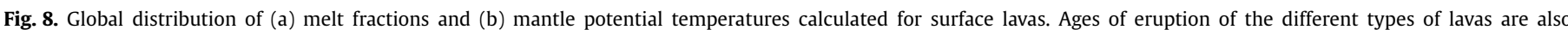
shown (Weider et al., 2012).

On Earth, such a process (or near-batch melting) is thought to occur beneath the thick crust of continental margins and in mantle plumes beneath continental and oceanic magmatic provinces (Bartels et al., 1991; Till et al., 2012). During batch decompression melting, the melt remains in equilibrium with its residue during ascent of the mantle parcel. In this case, the MSP records the last pressure-temperature conditions at which the melt was in equilibrium with the mantle (Bowen, 1928). For Mercury, we suggest that melting started at great depth within the mantle $(160-360 \mathrm{~km})$ and that the Fo-En-Liq MSP (Fig. 6b) record the extraction of the liquid from its mantle residue at the bottom of the ancient lithosphere. High degree of partial melting starting at great depth can also adequately explain the high $\mathrm{MgO}$ content of Mercurian lavas, and the relatively thick secondary volcanic crust of the planet (35 \pm 18 km; Padovan et al., 2015).

\subsection{Thermal evolution of the mantle and origin of the High-Mg ICP-HCT region}

Calculation of the pressure-temperature conditions of Fo-EnsLiq MSP for $\sim 5800$ surface compositions together with the calculation of the pressure-temperature path for each composition during adiabatic batch melting allow us to provide strong constraints on the thermal evolution of the planet. The older lavas from IcP-HCT (4.2-4.0 Ga) were produced by high degree of partial melting ( $F: 0.35 \pm 0.03$; Fig. $8 \mathrm{a}$ ) in a mantle with high $T_{\mathrm{p}}$ $\left(1510 \pm 40^{\circ} \mathrm{C}\right.$; Fig. $\left.8 \mathrm{~b}\right)$. In contrast, the lavas from the younger terrains (NVP, SP; 3.8-3.7 Ga) were produced by lower degrees of partial melting (NVP: $0.27 \pm 0.04$; SP: $0.28 \pm 0.03$ ) in a mantle with lower $T_{\mathrm{p}}$ (NVP: $1435 \pm 42^{\circ} \mathrm{C}$; SP: $1450 \pm 35^{\circ} \mathrm{C}$ ).

Lavas from the High-Mg IcP-HCT terrane require anomalously high mantle $T_{\mathrm{p}}\left(1648 \pm 25^{\circ} \mathrm{C}\right.$; Fig. 8b). This terrane $(>5 \times$ $10^{6} \mathrm{~km}^{2}$ ), located in the Northern Hemisphere, is characterized by generally low elevation and thinner than average crust (Smith et al., 2012; Weider et al., 2015). It has a higher than average crater density, supporting that this terrane represents one of the most ancient regions of Mercury's crust. We propose that the High-Mg IcP-HCT terrane was produced by decompression melting starting at great depth $(360 \mathrm{~km})$ and that these lavas are older than other lavas from IcP-HCT. This hypothesis implies that the mantle temperature was very high during the first hundreds of millions of years of Mercury's history and that the mantle was rapidly convecting. This rapid convection led to rapid cooling and $T_{\mathrm{p}}$ decreased significantly $\left(70^{\circ} \mathrm{C} / 0.1 \mathrm{Ga}\right.$ from 4.2 to $4.0 \mathrm{Ga}$ and $\sim 15-20^{\circ} \mathrm{C} / 0.1 \mathrm{Ga}$ from 4.0 to $3.7 \mathrm{Ga}$; Fig. 8b). High mantle temperature may result from the high heat flow at the mantle-core boundary also due to rapid convection in the hot core cooling (Nimmo, 2007). The strong secular cooling of the mantle during the early history of Mercury implies a strongly temperature dependent mantle viscosity with a high activation energy (Grove and Parman, 2004). It is also likely that early radioactive decay contributed heat to drive the high degree of mantle melting needed to form High-Mg IcP-HCT lavas. Recent estimates of heat production of the Mercurian mantle at $4.0 \mathrm{GPa}$ are high $\left(7 \times 10^{-12}-8 \times 10^{-12} \mathrm{~W} / \mathrm{kg}\right.$; Padovan et al., 2015) and would allow a high degree, batch adiabatic decompression melting of a fertile lherzolitic mantle (Kiefer, 2003).

It has also been proposed that the overall formation of the High-Mg terrane may be related to a large impact having penetrated into the mantle (Weider et al., 2015). Our experimental results do not provide evidence to rule out this hypothesis. However, our model has the advantage that a single process, adiabatic decompression melting during the progressive cooling of Mercury's mantle, can explain the temporal evolution of lava compositions, their melting extents and temperatures.

\subsection{Multiple mantle sources}

Charlier et al. (2013) proposed that the mantle source of the low-Mg IcP-HCT lavas was lherzolitic while the source of the high$\mathrm{Mg}$ IcP-HCT lavas was harzburgitic, suggesting that several mantle sources may have contributed to Mercury's magmatic activity. After more data on $\mathrm{Na}_{2} \mathrm{O}$ of surface compositions became available (Peplowski et al., 2014, 2015), it was apparent that most surface compositions for IcP-HCT as well as lavas from NVP and SP contain a significant and variable $\mathrm{Na}_{2} \mathrm{O}$ content which we have included in this new set of experiments. This translates to a range of clinopyroxene fraction in the mantle source and our results indicate that Mercurian lavas were produced by melting of lherzolitic source regions. From the variability in $\mathrm{Na}_{2} \mathrm{O}$ contents in these lavas we can infer that the mantle source regions must be variably enriched and contain $\sim 1.1$ to 1.9 wt.\% $\mathrm{Na}_{2} \mathrm{O}$. The variation of the $\mathrm{CaO}$ content of surface lavas is also remarkable. The highest $\mathrm{CaO}$ lavas (Fig. 2) are the high-Mg IcP-HCT lavas, and these are also the lavas with 
the highest sulfur contents (Weider et al., 2015). It is therefore likely that variations in the source regions also involve variations in the CaS and MgS components. Contrasting mantle lithologies on Mercury may have formed by lateral and/or vertical compositional stratification of the mantle during crystallization of a magma ocean (Charlier et al., 2013), by vertical migration of heterogeneous manthe parcels due to convection of mantle cells (Tosi et al., 2013), or by progressive evolution of mantle sources by melt extraction through time. The most likely source material for Mercury is an $\mathrm{EH}$ chondrite. The $\mathrm{Na}_{2} \mathrm{O}$ and $\mathrm{S}$ contents of $\mathrm{EH}$ chondrites are high enough to produce the abundances that we observe in Mercury surface lavas (Malavergne et al., 2010). However, the lavas on Mercury's could not be produced by direct melting of an EH chondrite bulk composition, because the $\mathrm{Mg} / \mathrm{Si}$ ratio is too low and such a mantle would be dominated by enstatite (Berthet et al., 2009; Malavergne et al., 2014). Mercurian lavas must come from olivinerich source regions and the youngest lavas (NVP) are strongly silica undersaturated, nepheline-normative melts (Fig. 5). We suggest that early magma ocean solidification and core formation under highly reducing conditions (IW-4 to IW-6; McCubbin et al., 2012) led to the segregation of a Si-rich core and Mg-rich silicate residue (Chabot et al., 2014). This high-Mg mantle was then re-melted in the time frame of 4.2 to $3.7 \mathrm{Ga}$ to produce the Mercurian surface lavas.

\section{Conclusions}

Our calculations of surface compositions of Mercury together with projections in phase diagrams allow us to suggest that Mercurian basalts have been produced by partial melting of compositionally heterogeneous lherzolitic sources. The near liquidus phase relationships for NVP and high-Mg IcP-HCT basalts and the thermodynamic modelling that we performed both suggest that magmas were separated from their mantle residues at relatively shallow depth in the mantle. Batch adiabatic decompression and melting that started near the core-mantle boundary at $4.2 \mathrm{Ga}$ and progressively moved to shallower depths (200 km at $3.7 \mathrm{Ga}$ ) record strong secular cooling of the mantle during the early history of Mercury.

\section{Acknowledgements}

ON acknowledges support from the von Humboldt Foundation and from a Marie Curie Intra-European Fellowship (SULFURONMERCURY - 327046) within the 7th European Community Framework Programme. ON also acknowledges support from the DFG Core Facility for High-Pressure Research from the German Science Foundation for the high-pressure experiments performed at BGI. BC was supported by the von Humboldt Foundation, a Back to Belgium Grant of BELSPO, and the BRAIN-be program (BR/143/A2/COME-IN). TLG was supported by NASA grant NNX12AH80G. Discussions with O. Shorttle were highly appreciated. We appreciate comments from C. Sotin (editor), N. Chabot and an anonymous reviewer that significantly improved the quality of the paper.

\section{Appendix A. Supplementary material}

Supplementary material related to this article can be found online at http://dx.doi.org/10.1016/j.epsl.2016.01.030.

\section{References}

Ahern, J.L., Turcotte, D.L., 1979. Magma migration beneath an ocean ridge. J. Geophys. Res. 45, 115-122.

Andersen, O., 1915. The system anorthite-forsterite-silica. Am. J. Sci. 39, 407-454.
Asimow, P.D., Longhi, J., 2004. The significance of multiple saturation points in the context of polybaric near-fractional melting. J. Petrol. 45, 2349-2367.

Bartels, K., Kinzler, R., Grove, T., 1991. High pressure phase relations of primitive high-alumina basalts from Medicine Lake volcano, northern California. Contrib. Mineral. Petrol. 108, 253-270.

Berthet, S., Malavergne, V., Righter, K., 2009. Melting of the Indarch meteorite (EH4 chondrite) at $1 \mathrm{GPa}$ and variable oxygen fugacity: implications for early planetary differentiation processes. Geochim. Cosmochim. Acta 73, 6402-6420.

Boujibar, A., Righter, K., Pando, K., Danielson, L.R., 2015. Experimental constraints on the chemical differentiation of Mercury's mantle. In: Lunar and Planetary Science Conference, vol. XLVI, p. 2544.

Bowen, N.L., 1928. The Evolution of the Igneous Rocks. Princeton University Press, Princeton, NJ.

Brown, S.M., Elkins-Tanton, L.T., 2009. Compositions of Mercury's earliest crust from magma ocean models. Earth Planet. Sci. Lett. 286, 446-455.

Byrne, P.K., Klimczak, C., Williams, D.A., Hurwitz, D.M., Solomon, S.C., Head, J.W., Preusker, F., Oberst, J., 2013. An assemblage of lava flow features on Mercury. J. Geophys. Res., Planets 188, 1303-1322.

Cartier, C., Hammouda, T., Doucelance, R., Boyet, M., Devidal, J.-L., Moine, B., 2014 Experimental study of trace element partitioning between enstatite and melt in enstatite chondrites at low oxygen fugacities and $5 \mathrm{GPa}$. Geochim. Cosmochim. Acta $130,167-187$.

Chabot, N.L., Wollack, E.A., Klima, R.L., Minitti, M.E., 2014. Experimental constraints on Mercury's core composition. Earth Planet. Sci. Lett. 390, 199-208.

Charlier, B., Grove, T.L., Zuber, M.T., 2013. Phase equilibria of ultramafic compositions on Mercury and the origin of the compositional dichotomy. Earth Planet. Sci. Lett. 363, 50-60

Corgne, A., Keshav, S., Wood, B.J., McDonough, W.F., Fei, Y., 2008. Metal-silicate partitioning and constraints on core composition and oxygen fugacity during Earth accretion. Geochim. Cosmochim. Acta 72, 574-589.

Denevi, B.W., Ernst, C.M., Meyer, H.M., Robinson, M.S., Murchie, S.L., Whitten, J.L., Head, J.W., Watters, T.R., Solomon, S.C., Ostrach, L.R., Chapman, C.R., Byrne, P.K., Klimczak, C., Peplowski, P.N., 2013. The distribution and origin of smooth plains on Mercury. J. Geophys. Res., Planets 118, 891-907.

Fogel, R.A., 2005. Aubrite basalt vitrophyres: the missing basaltic component and high-sulfur silicate melts. Geochim. Cosmochim. Acta 69, 1633-1648.

Gaetani, G.A., Grove, T.L., 1999. Wetting of mantle olivine by sulfide melt: implications for Re/Os ratios in mantle peridotite and late-stage core formation. Earth Planet. Sci. Lett. 169, 147-163.

Ghiorso, M.S. Sack, R.O., 1995. Chemical mass transfer in magmatic processes IV. A revised and internally consistent thermodynamic model for the interpolation and extrapolation of liquid-solid equilibria in magmatic systems at elevated temperatures and pressures. Contrib. Mineral. Petrol. 119, 197-212.

Ghiorso, M.S., Hirschmann, M.M., Reiners, P.W., Kress III, V.C., 2002. The pMELTS: a revision of MELTS for improved calculation of phase relations and major element partitioning related to partial melting of the mantle to $3 \mathrm{GPa}$. Geochem. Geophys. Geosyst. 3, 1030.

Grove, T.L., Parman, S.W., 2004. Thermal evolution of the Earth as recorded by komatiites. Earth Planet. Sci. Lett. 219, 173-187.

Gupta, A.K., Green, D.H., Taylor, W.R., 1987. The liquidus surface of the system forsterite-nepheline-silica at $28 \mathrm{~kb}$. Am. J. Sci. 287, 560-565.

Head, J.W., Chapman, C.R., Strom, R.G., Fassett, C.I., Denevi, B.W., Blewett, D.T., Ernst, C.M., Watters, T.R., Solomon, S.C., Murchie, S.L., Prockter, L.M., Chabot, N.L., Gillis-Davis, J.J., Whitten, J.L., Goudge, T.A., Baker, D.M.H., Hurwitz, D.M., Ostrach, L.R., Xiao, Z., Merline, W.J., Kerber, L., Dickson, J.L., Oberst, J., Byrne, P.K., Klimczak, C., Nittler, L.R., 2011. Flood volcanism in the northern high latitudes of Mercury revealed by MESSENGER. Science 333, 1853-1856.

Herzberg, C.T., 1983. Solidus and liquidus temperatures and mineralogies for anhydrous garnet-lherzolite to 15 GPa. Phys. Earth Planet. Inter. 32, 193-202.

Hess, P.C., 1992. Phase equilibria constraints on the origin of ocean floor basalts. In: Phipps Morgan, J., Blackman, D.K., Sinton, J.M. (Eds.), Mantle Flow and Melt Migration. American Geophysical Union, pp. 67-102.

Hirschmann, M.M., 2000. Mantle solidus: experimental constraints and the effect of peridotite composition. Geochem. Geophys. Geosyst. 1.

Hirschmann, M.M., Asimow, P.D., Ghiorso, M.S., Stolper, E.M., 1999. Calculation of peridotite partial melting from thermodynamic models of minerals and melts. III. Controls on isobaric melt production and the effect of water on melt production. J. Petrol. 40, 831-851.

Katz, R.F., Spiegelman, M., Langmuir, C.H., 2003. A new parameterization of hydrous mantle melting. Geochem. Geophys. Geosyst. 4, 1073.

Kiefer, W.S., 2003. Melting in the martian mantle: shergottite formation and implications for present-day mantle convection on Mars. Meteorit. Planet. Sci. 38, 1815-1832.

Kiefer, W.S., Filiberto, J., Sandu, C., Li, Q., 2015. The effects of mantle composition on the peridotite solidus: implications for the magmatic history of Mars. Geochim. Cosmochim. Acta 162, 247-258.

Klein, E.M., Langmuir, C.H., 1987. Global correlations of ocean ridge basalt chemistry with axial depth and crustal thickness. J. Geophys. Res. 92, 8089-8115.

Klimczak, C., Watters, T.R., Ernst, C.M., Freed, A.M., Byrne, P.K., Solomon, S.C., Blair, D.M., Head, J.W., 2012. Deformation associated with ghost craters and basins in 
volcanic smooth plains on Mercury: strain analysis and implications for plains evolution. J. Geophys. Res., Planets 117, E00L03.

Kushiro, I., 1972. Determination of liquidus relations in synthetic silicate systems with electron probe analysis: the system forsterite-diopside-silica at 1 atmosphere. Am. Mineral. 57, 1260-1271.

Liu, T.-C., Presnall, D.C., 1990. Liquidus phase relationships on the join anorthiteforsterite-quartz at $20 \mathrm{kbar}$ with applications to basalt petrogenesis and igneous sapphirine. Contrib. Mineral. Petrol. 104, 735-742.

Longhi, J., 1987. Liquidus equilibria and solid solution in the system $\mathrm{CaAl}_{2} \mathrm{Si}_{2} \mathrm{O}_{8}-$ $\mathrm{Mg}_{2} \mathrm{SiO}_{4}-\mathrm{CaSiO}_{3}-\mathrm{SiO}_{2}$ at low pressure. Am. J. Sci. 287, 265-331.

Malavergne, V., Toplis, M.J., Berthet, S., Jones, J., 2010. Highly reducing conditions during core formation on Mercury: implications for internal structure and the origin of a magnetic field. Icarus 206, 199-209.

Malavergne, V., Cordier, P., Righter, K., Brunet, F., Zanda, B., Addad, A., Smith, T. Bureau, H., Surblé, S., Raepsaet, C., Charon, E., Hewins, R.H., 2014. How Mercury can be the most reduced terrestrial planet and still store iron in its mantle. Earth Planet. Sci. Lett. 394, 186-197.

Marchi, S., Chapman, C.R., Fassett, C.I., Head, J.W., Bottke, W.F., Strom, R.G., 2013. Global resurfacing of Mercury 4.0-4.1 billion years ago by heavy bombardment and volcanism. Nature 499, 59-61.

McCoy, T.J., Dickinson, T.L., Lofgren, G.E., 1999. Partial melting of the Indarch (EH4) meteorite: a textural, chemical, and phase relations view of melting and melt migration. Meteorit. Planet. Sci. 34, 735-746.

McCubbin, F.M., Riner, M.A., Vander Kaaden, K.E., Burkemper, L.K., 2012. Is Mercury a volatile-rich planet? Geophys. Res. Lett. 39, L09202.

McKenzie, D.P., Bickle, M.J., 1988. The volume and composition of melt generated by extension of the lithosphere. J. Petrol. 29, 625-679.

Métrich, N., Berry, A.J., O’Neill, H.S.C., Susini, J., 2009. The oxidation state of sulfur in synthetic and natural glasses determined by X-ray absorption spectroscopy. Geochim. Cosmochim. Acta 73, 2382-2399.

Nimmo, F., 2007. 8.02 - energetics of the core. In: Romanowicz, B., Dziewonski, A., Schubert, G. (Eds.), Deep Earth Seismology. In: Treatrise in Geophysics, vol. 1. Elsevier, Amsterdam, pp. 31-65.

Nittler, L.R., Starr, R.D., Weider, S.Z., McCoy, T.J., Boynton, W.V., Ebel, D.S., Ernst, C.M., Evans, L.G., Goldsten, J.O., Hamara, D.K., Lawrence, D.J., McNutt, R.L., Schlemm, C.E., Solomon, S.C., Sprague, A.L., 2011. The major-element composition of Mercury's surface from MESSENGER X-ray spectrometry. Science 333, 1847-1850.

Osborn, E.F., Tait, D.B., 1952. The system diopside-forsterite-anorthite. Am. J. Sci. Bowen Volu, 413-433.

Padovan, S., Wieczorek, M.A., Margot, J.-L., Tosi, N., Solomon, S.C., 2015. Thickness of the crust of Mercury from geoid-to-topography ratios. Geophys. Res. Lett. 42, 1029-1038.

Peplowski, P.N., Lawrence, D.J., Rhodes, E.A., Sprague, A.L., McCoy, T.J., Denevi, B.W. Evans, L.G., Head, J.W., Nittler, L.R., Solomon, S.C., Stockstill-Cahill, K.R., Weider, S.Z., 2012. Variations in the abundances of potassium and thorium on the surface of Mercury: results from the MESSENGER gamma-ray spectrometer. J. Geophys. Res., Planets 117, E00L04.

Peplowski, P.N., Evans, L.G., Stockstill-Cahill, K.R., Lawrence, D.J., Goldsten, J.O., McCoy, T.J., Nittler, L.R., Solomon, S.C., Sprague, A.L., Starr, R.D., Weider, S.Z., 2014. Enhanced sodium abundance in Mercury's north polar region revealed by the MESSENGER gamma-ray spectrometer. Icarus 228, 86-95.
Peplowski, P.N., Lawrence, D.J., Feldman, W.C., Goldsten, J.O., Bazell, D., Evans, L.G. Head, J.W., Nittler, L.R., Solomon, S.C., Weider, S.Z., 2015. Geochemical terranes of Mercury's northern hemisphere as revealed by MESSENGER neutron measurements. Icarus 253, 346-363.

Presnall, D.C., Dixon, S.A., Dixon, J.R., O’Donnell, T.H., Brenner, N.L., Schrock, R.L., Dycus, D.W., 1978. Liquidus phase relations on the join diopside-forsteriteanorthite from 1 atm to 20 kbar: their bearing on the generation and crystallization of basaltic magma. Contrib. Mineral. Petrol. 66, 203-220.

Presnall, D.C., Dixon, J.R., O’Donnell, T.H., Dixon, S.A., 1979. Generation of mid-ocean ridge tholeiites. J. Petrol. 20, 3-35.

Sen, G., Presnall, D.C., 1984. Liquidus phase relationships on the join anorthiteforsterite-quartz at $10 \mathrm{kbar}$ with applications to basalt petrogenesis. Contrib. Mineral. Petrol. 85, 404-408.

Shorttle, O., MacLennan, J., Lambart, S., 2014. Quantifying lithological variability in the mantle. Earth Planet. Sci. Lett. 395, 24-40.

Smith, D.E., Zuber, M.T., Phillips, R.J., Solomon, S.C., Hauck, S.A., Lemoine, F.G. Mazarico, E., Neumann, G.A., Peale, S.J., Margot, J.-L., Johnson, C.L., Torrence, M.H., Perry, M.E., Rowlands, D.D., Goossens, S., Head, J.W., Taylor, A.H., 2012 Gravity field and internal structure of Mercury from MESSENGER. Science 336 214-217.

Sorbadere, F., Schiano, P., Métrich, N., 2013. Constraints on the origin of nephelinenormative primitive magmas in island arcs inferred from olivine-hosted melt inclusion compositions. J. Petrol. 54, 215-233.

Taylor, G.J., Scott, E.R.D., 2003. Mercury. In: Heinrich, D.H., Karl, K.T. (Eds.), Treatise on Geochemistry. Pergamon, Oxford, pp. 477-485.

Thomas, R.J., Rothery, D.A., Conway, S.J., Anand, M., 2014. Long-lived explosive volcanism on Mercury. Geophys. Res. Lett. 41, 6084-6092.

Till, C.B., Grove, T.L., Krawczynski, M.J., 2012. A melting model for variably depleted and enriched lherzolite in the plagioclase and spinel stability fields. J. Geophys. Res., Solid Earth 117, B06206.

Tosi, N., Grott, M., Plesa, A.-C., Breuer, D., 2013. Thermochemical evolution of Mercury's interior. J. Geophys. Res., Planets B, 06206.

Vander Kaaden, K.E., McCubbin, F.M., 2016. The origin of boninites on Mercury: an experimental study of the northern volcanic plains lavas. Geochim. Cosmochim. Acta 173, 246-263.

Walter, M.J., Presnall, D.C., 1994. Melting behavior of simplified lherzolite in the system $\mathrm{CaO}-\mathrm{MgO}-\mathrm{Al}_{2} \mathrm{O}_{3}-\mathrm{SiO}_{2}-\mathrm{Na}_{2} \mathrm{O}$ from 7 to 35 kbar. J. Petrol. 35, 329-359.

Weider, S.Z., Nittler, L.R., Starr, R.D., McCoy, T.J., Stockstill-Cahill, K.R., Byrne, P.K., Denevi, B.W., Head, J.W., Solomon, S.C., 2012. Chemical heterogeneity on Mercury's surface revealed by the MESSENGER X-ray spectrometer. J. Geophys. Res. 117, E00L05.

Weider, S.Z., Nittler, L.R., Starr, R.D., McCoy, T.J., Solomon, S.C., 2014. Variations in the abundance of iron on Mercury's surface from MESSENGER X-ray spectrometer observations. Icarus 235, 170-186.

Weider, S.Z., Nittler, L.R., Starr, R.D., Crapster-Pregont, E.J., Peplowski, P.N., Denevi, B.W., Head, J.W., Byrne, P.K., Hauck II, S.A., Ebel, D.S., Solomon, S.C., 2015. Evidence for geochemical terranes on Mercury: global mapping of major elements with MESSENGER's X-ray spectrometer. Earth Planet. Sci. Lett. 416, 109-120.

Zolotov, M.Y., Sprague, A.L., Hauck, S.A., Nittler, L.R., Solomon, S.C., Weider, S.Z., 2013 The redox state, $\mathrm{FeO}$ content, and origin of sulfur-rich magmas on Mercury. J. Geophys. Res., Planets 118, 138-146. 